\title{
The Maintenance of Health in the Tropics....
}

Ornia
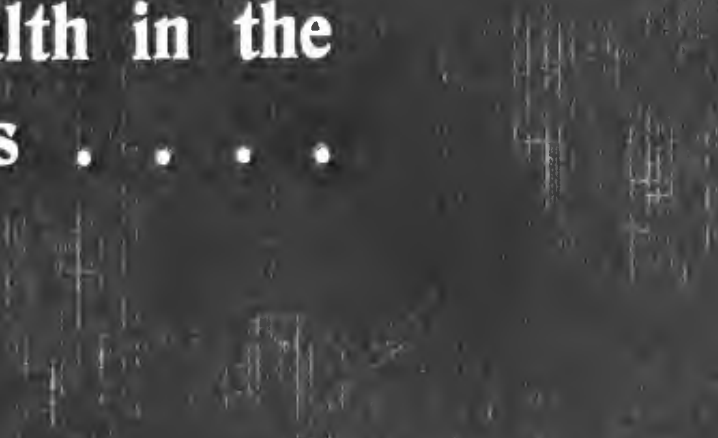

y

SECOND EDITION

SIMPSON 

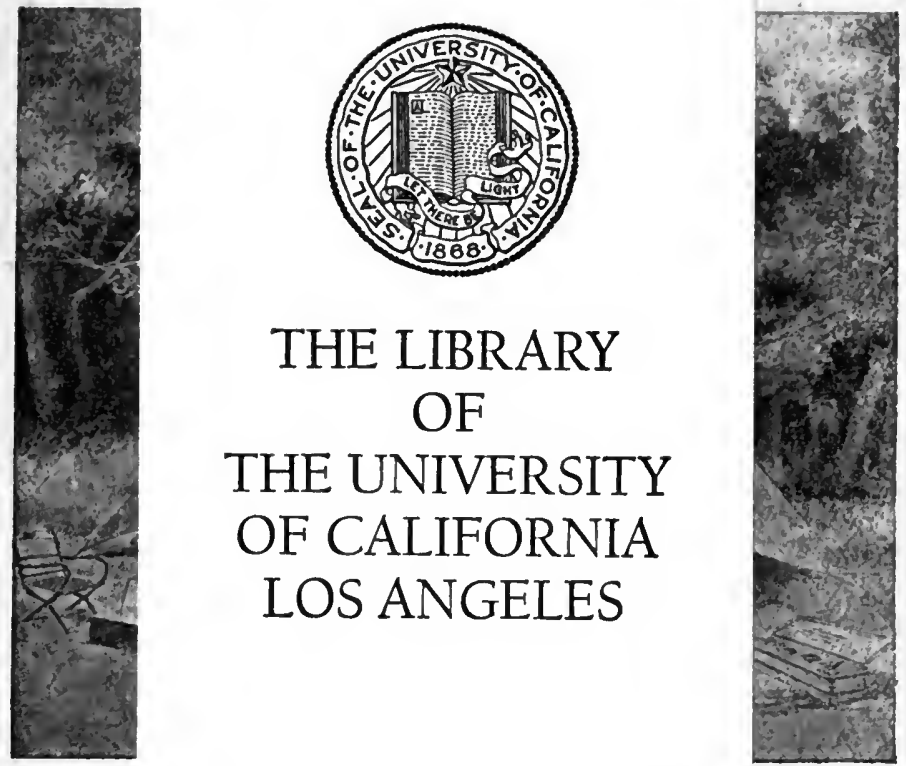

For

THE LIBRARY

OF

THE UNIVERSITY

OF CALIFORNIA

LOS ANGELES

\title{
lonies
}

JOHiv cuUIIVUI UIN $\alpha$ uU., LTD.

Who know exactly what is required, and where everything can be seen at . .

\section{SARDINIA HOUSE, SARDINIA ST., KINGSWAY, W.C.}

\author{
(Adjoining the London Opera House).
}

Tents and Camp Furniture of every Description, Mosquito Nets, Mosquito Houses, Cooking and Mess Utensils, Airtight and Watertight Steel Boxes, Uniforms, Clothing, Boots, Saddlery, Guns, Rifles, Revolvers, \&c. Provisions, Wines and Spirits, \&c.

INSURANCES AND AGENCY BUSINESS OF EVERY DESCRIPTION. GOODS BOUGHT ON COMMISSION. 


\section{AS a DRINK for HOT CLIMATES}

there is nothing to equal

\section{BARLEY WATER}

made from

\section{ROBINSON'S "patan" BARLEY}

It is delightfully refreshing and thirstquenching. Invigorates both mind and body, imparts endurance and has none of the ill effects of acid or alcoholic drinks.

\section{The BEST FOOD for INFANTS}

up to 8-10 months old, is Cows' Milk (either natural or dried in powder form) diluted with BARLEY WATER made from

\section{ROBINSON'S "paran" BARLEY}

Perfect nutrition, sound sleep, and freedom from digestive troubles are some of the advantages of using this diet.

\section{For BABIES when WEANED} also for Nursing Mothers, Invalids, and the Aged, the best food is GRUEL made (with milk) from

ROBINSON'S "ppater" CROATS

KEEN, ROBINSON \& CO., LTD., LONDON. 


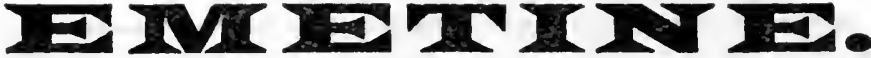

\section{Hydrochlorid (Whiffes's) Hydrobromid}

For Hypodermic Injection.

"Emetine is specific in Amabic Dysentery."-E. R. Wutmore, Nezu Jork Medical Journal.

Specific Curative Action in Amcebic Dysentery and Hepatitis. Further Success of Treatment of Tubercular Hzemoptysis. Treatment of Intestinal Hamorrhage in Typhoid. Remedy for Haemorrhage in Diabetes.

For Latest Reports see Pamphlet, forwarded on Application.

"The Ney Remedy In Amceblc Disease." Vide British Medical Journal, August 24th, 1912, pp. 405-408.

"Emetine for Hzmoptysis: The result is surprising, hamorrhage from the lung ceasing at once."-Prof. C. Flandin, vide Press Mfidicale, Paris, Sept. 24th.

"Emetine for Hrmorrhage of the Digestion Tract In Diabetes: Emetine Hydrochloride possesses powerful hremostatic properties administered in quantities of 6 centigrammes hypodermically, which constitute a valuable remedy in serious hrenorrbage of the digestive tract in Diabetes, particularly as no inconvenience altends its use." Dr. Rênon, vide Le Concours Mídical, p. 2947.

EMETINE SALTS are obtainable in the form of

EMETINE HYDROCHLORIDE in One Gramme Tubes. EMETINE HYDROBROMIDE in One Gramme Tubes.

For Hypodermic Injection, we prepare Sterilized Solutions ready for use in Ampoules of the following strengths:-

Ampoules, Emetine Hydrochloride, $\frac{1}{4}$ grain ("0162 gramme) in I c.c. solution Do. do. do. $\frac{1}{2}$ grain ( 0324 gramme) in 1 c.c. do.

Do. Emetine Hydrobromide, 1 grain ( 0162 gramme) in 1 c.c. do.

Do. do. do. $\frac{7}{2}$ grain (.0324 gramme) in 2 c.c. do. PACKED IN BOXES OF ONE DOZEN

AMPOULES, READY FOR POSTING.

We supply TABLETS for hypodermic use $\frac{1}{4}$ grain, $\frac{1}{3}$ rd grain and $\frac{1}{2}$ grain, 12 tablets in a tube.

WE ARE ALSO MANUPACTURERS OF THE FOLLOWING Pharmaceutical Preparations:

Strychnine, Theobromine, Nicotine \& Quinine Salts, Cinchona Barks \& Alkaloids.

\section{IODINE \& BROMINE PREPARATIONS}

Mercurials. Refined Camphor.

MORPHINE \& CODEINE Alkaloids and Salts.

Opium \& all Opium Derivatives.

May be obtained by ordering Whiffen's Brand, from all Chemists and Wholesale Drug Houses in the United Kingdom and Abroad, or direct from-

WHIFFEN \& SONS, Ltd., Battersea, London, S.W.

Telegrams: "Whiffen, London." Telephones: 254, 255 Battersea.

Codes for telegraphing: A B C; Lieber's.

Contractors to the War Office, Admiralty and Allied Governments. 


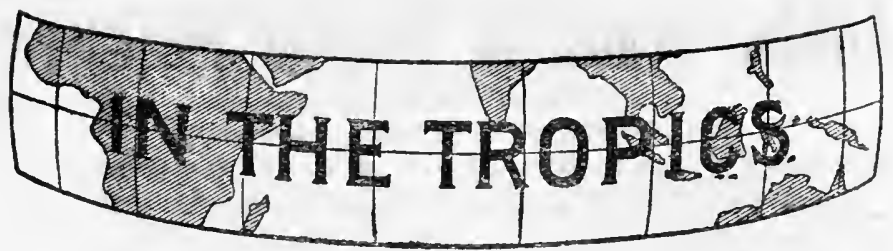

Stanley, Emin Pasha and many other great pioneers proved the reliability of

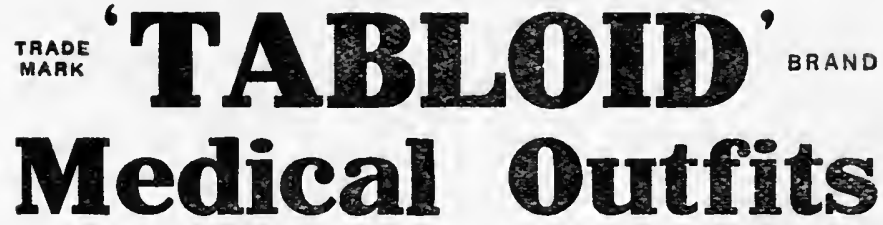

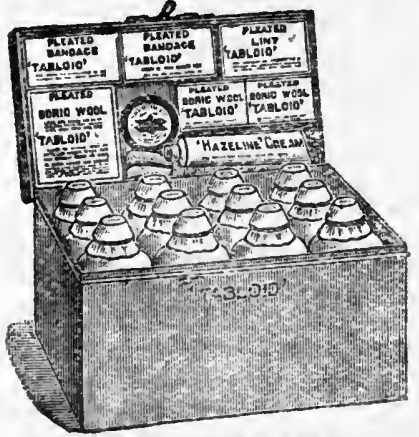

Measurements: 8$\} \times 48 \times 5 \%$ í.

Outfit No. 258, as shown here, is an excellent example. Can be fitted to afford your health the greatest possible protection against any climate.

The medicaments are perfectly pure, active, clinateproof and in ready-to-take doses. No waste, no trouble, no loss by breakage or deterioration, no risks.

Interesting Booklet, "Modern Medical Equipments," Post free, Send a posteard to-

留

35, Snow IIIl Buildings, London, E.C. 


\section{London School of Tropical Medicine.}

(UNIVERSITY OF LONDON.)

Under the Auspices of His Majesty's Government.

COINAUGIXI ROAD, FUEXIR DOCXE, E.

In connection with the Hospitals of the BEAMEN'S HOSPITAL SOCIETY.

TIIE SEAMEN'S HOSPITAL SOCIETY was established in the year 1821 and incorporated in 1833 , and from time to time has been enlarged and extended. It now consists of the Dreadnought Hospital, Greenwich; the Royal Victoria and Albert Docks Hospital; the East and West India Docks Dispensary ; and the Gravesend Dispensary.

Oxer 25,000 Patients treated annually. Of this number many are Cases of Tropical Disease.

The School buildings are situated within the grounds of the Royal Victoria and Albert Docks Hospital.

MEDICAL STAFF OF THE HOSPITAL AND LECTURERS IN THE TROPICAL SCHOOL.

Sir PATRICK MANSON, G.C.M.G., F.R.S., LL.D., M.D., F.R.C.P.

Professor R. TANNER HEWLETT, M.D., M.R.C.I.

JAS. CANTLIE, Esq., M.B., F.R.C.S.

L. VERNON CARGILL, Esq., F.R.C.S.

Professor W. J. SIMPSON, M.D., F.R.C.P.

L. W. SAMBON, Esq., M.D.

J. M. H. MACLEOD, Esq., M.D.,

E. TREACHER COLLINS, Esq.,
F. M. SANDIVITH, Esq., C.M.G., M.D., F.R.C.P.

C. W. DANIELS, Esq., M.B., F.R.C.P. G. C. LOW, Esq., M.D.

Col. J. J. PRATT, I.M.S., F.R.C.S. Helminthologist-R. T. LEIPER, Esq., U.Sc., M. B.

Entomologist-Col. A. ALCOCK, C.I.E., I. M.S.

Protozonlogist-J. G. THOMSON, M.B., Ch. B.

Dean-Sir HAVELOCK CHARLES, G.C.V.O.

Director-H. B. NEWHAM, Esq., M.D., M.R.C.P.

Secretary-P. J. MICHELLI, Esq., C.M.G.

\section{LECTURES AND DEMONSTRATIONS DAILY BY MEMBERS OF THE STAFF.}

There are three Sessions yearly of three months each, viz. : from 1st October to 3 Ist December, from 15th January 10 14th April, and from Ist May to 3 Ist July inclusive. Women Graduates are received as Students.

Certificates are granted after Examination at the end of each Session Fee for course $\mathcal{E 1 6 1 6 s . ; ~ s h o r t e r ~ p e r i o d s ~ b y ~ a r r a n g e m e n t . ~}$

Students can be provided with Board and Residence, or partial Board at the School.

Medical men requiring posts in the Tropics may apply to the Secretary at the School.

A prospectus, with the general course of study, can be had on application.

Seamen's Hospital, Greenwich, S.E. 


\section{CLAYTON}

\section{DISINFECTING SYSTEM}

The only

SULPHUR SYSTEM officially approved for DISINFECTION as well as for DESTRUCTION OF RATS, INSECTS (with their larvæ and their eggs), and all other VERMIN. Everything Disinfected in situ, no handling or removing to disinfecting chambers required.

Full partlculars from

The Clayton Fire Extinguishing and Disinfecting Company, Limited,

\section{2, CRAVEN STREET, LONDON, W.C.}

\section{Contractors to}

WAR OFFICE, ADMIRALTY, CROWN AGENTS, INDIA OFFICE and FOREIGN GOVERNMENTS. 
$\frac{\text { PORTABLE DISINFECTOR }}{\text { KLORENCE ATENT. }}$

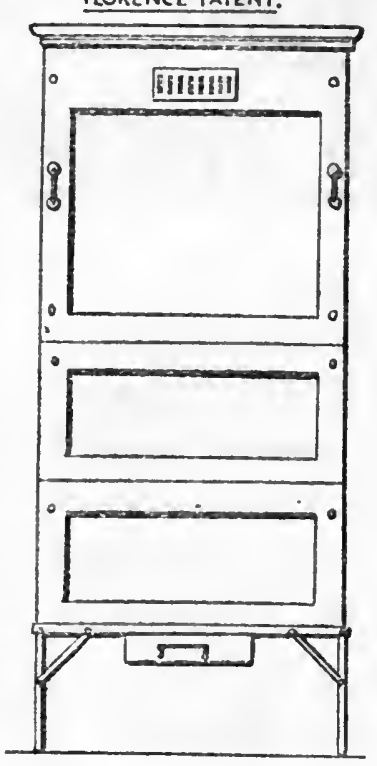

- FRONT ELEVATIONShowing Disinfector open for ase.

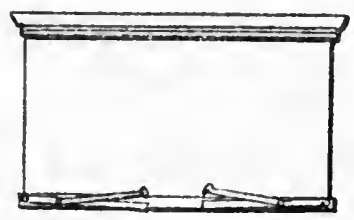

FRONT ELEVATION Shewing Disinfector closed for transport. Catalogue with Testimonials.

"NEWMAN"

PORTAB LE DISINFECTOR AS SUPPLIED TO H. M. War Office, Belgian Government, British and other Red

Cross Societies, Governor of Egypt, $\& c$.

\section{SIMPLE IN CONSTRUCTION AND USE.}

Largest output of any Disinfector on the market.

\section{ABSOLOTELY RELIABLE.}

Sole Patentees and Makers:

The London Warming \& Ventilating Co., Ltd., 20, NEWMAN STREET, LONDON, W. 


\section{THE}

\section{THRESH DISINFECTOR CO.}

Contractors to H.M. War Office, The Admirally, India Office, Ec.

\section{Dr. THRESH'S}

Current Steam Disinfectors

Portable Machines on Two or

Four Wheels. Arranged for

Horse Traction or Bullock Draught.

Special High Capacity Pressure

Machines on Motor Wagons.

Stationary ${ }^{*}$ Machines

Furnace-Heated

or

Steam-Heated

* $*$

The Emergency Disinfector Inexpensive, Reliable, Readily Portable.

For Cottage Hospitals,

Rural Districts,

Education Authorities.

$*$

The Mackenzie Spray

For Disinfecting Hospital Wards,

Barracks, Schools,

Go-Downs,

Huts, \&c., \&c.

4, Central Buildings, Westminster, S.W.

Telegrams: "Threshdisco-Vic, London."

'Phone: Victoria, 4781-4782. 
THERE is no item of the dietary more direct bearing upon the maintenance of good Health than Milk. The tropical heat, the lack of good pasture lands, and the insanitary conditions, combine to make the use of fresh milk highly dangerous even if it be possible to obtain a supply at all.

\section{MILKMAID BRAND CONDENSED MILK}

on the other hand, is always perfectly fresh and pure. It is quite unaffected by the hottest climate, is absolutely free from bacteria, and in addition is essentially portable, and will keep good for any length of time if the tin is unopened.

A full list of the Company's depots throughout the zuorld, together with a book of recites of numerous dishes that may lie prepared with Milknaid Milk, will be sent free on application to the Anglo. Squiss Condensed Milk Co., B. Export Dept., 6 \& 8, Eastcheap, E.C. 



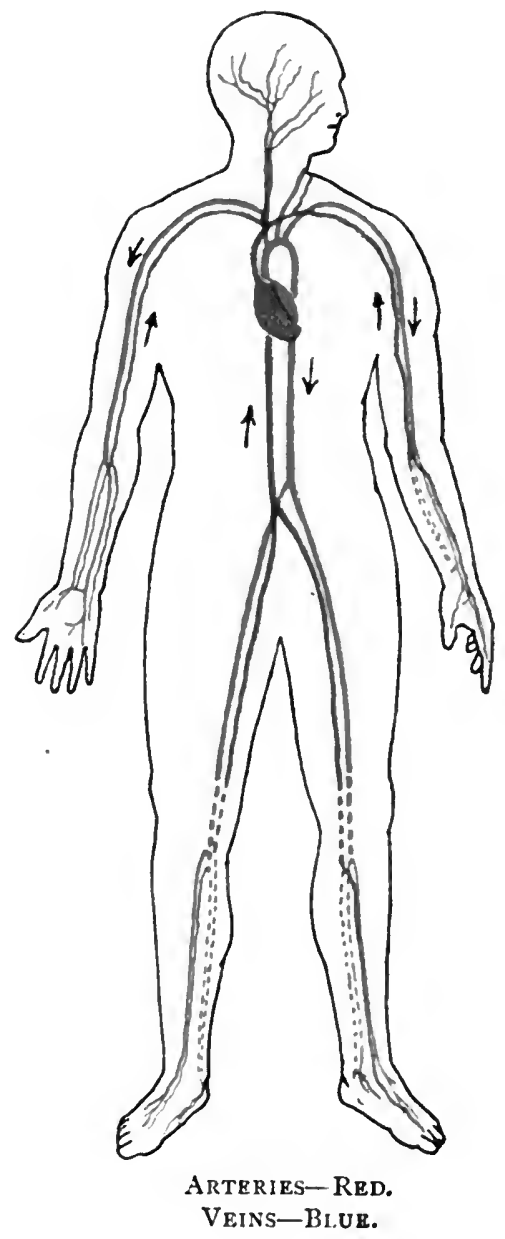




\section{The Maintenance of Health}

in the Tropics

BY

\section{W. J. SIMPSON, C.M.G., M.D., F.R.C.P.}

Professor of Hygiene and Public Health, Unizersity of Lonion, King's College; and Tecturer on Trofical Hygiene at the London School of Tropical Medicine

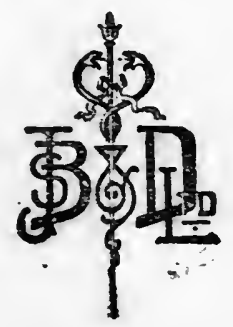

Published under the auspices of The London School of Tropical Medicine

BY

JOHN BALE, SONS \& DANIELSSON, LTD. OXFORD HOUSE

83-91, GREAT TITCHFIELD STREET, OXFORD STREET, W. 


\section{THE "P., D. \& Co." \\ Medicine Chests \& Cases}

are conyenient, practical and thoroughly

satisfactory outfits for the use of

Trayellers and Residents in all countries.

The "P., D. \& Co." Medicine Chests and Cases are supplied in a variety of sizes and designs at prices ranging from $£ 010$ s. Od. to $£ 1212 \mathrm{~s}$. Od., with contents adapted to meet any requirement.

Concentrated Medicines

(Standardised)

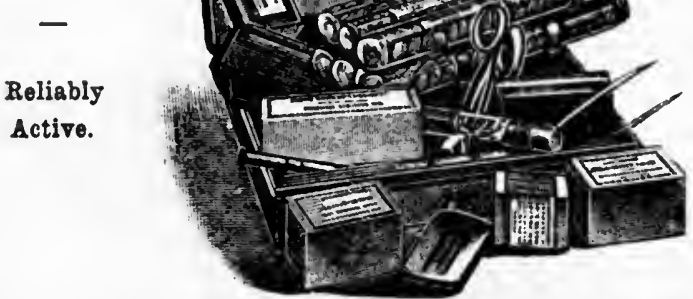

The "Tropical" Medicine Case.

In japanned metal, $7 \frac{1}{2}$ by $6 \frac{1}{2}$ by $1 \frac{1}{1}$ inches. Weight, fitted complete, $3 \frac{1}{1}$ pounds.

Illustrated Descriptive List will be sent upon request.

\section{PARIEE, DAYIS \& CO.,} 50, Beak Street, Regent Street, LONDON, $W$. 


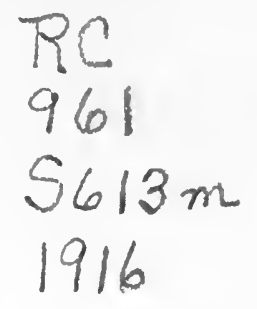

\section{PREFACE TO THE SECOND EDITION.}

ThE first edition of this handbook on the Maintenance of. Health in the Tropics being exhausted, I have taken the opportunity of bringing the present issue up to date.

I am indebted to Colonel Alcock, C.I.E., F.R.S., for revision of the Chapter on Snakes.

$$
\text { W. J. SIMPSON. }
$$

King's College,

1916. 
ALL RIGHTS RESERVED. 


\section{PREFACE.}

THIS handbook on the Maintenance of Health in the Tropics is written at the request of the Committee of the London School of Tropical Medicine, and is published under their auspices. It is felt that a small manual dealing with Personal Hygiene in a simple and popular manner is much needed, and would be very useful to those residing in or visiting the tropics.

$$
\text { W. J. SIMPSON. }
$$

King's College,

March, 1905. 


\section{On Resisting Disease}

An elaborate series of investigations recently conducted at the Frant Forest Sanatorium demonstrated in a remarkable manner the power of Virol to increase the natural defensive powers of the body against the diseases of bacterial origin.

By these experiments it was proved that in the case of patients fed on Virol the white cells of the blood destroyed three times as many of the germs of tuberculosis in a given time as was the case when the patients had not been fed on Virol.

Similar results were obtained in the Monsall Fever Hospital, Manchester. The importance of Virol in all febrile conditions, and especially in the case of young children who are so liable to infection, is therefore due not only to its remarkable tissue building properties, but also to the fact that Virol is the only food that has been proved to definitely raise the opsonic index of the patient.

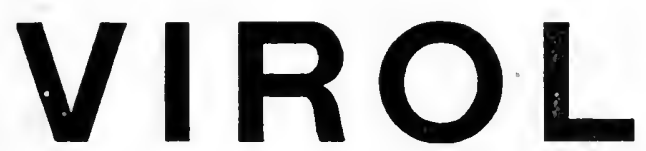

Used in more than 1,000 Hospitals in Great Britain. 


\section{CONTENTS.}

\section{CHAPTER I.}

Climate and Personal Precautions

... $\quad .$.

Climate.-A European requires to exercise reasonable care for his health in the tropics.-Precautions against undue exposure to the sun's rays.-Heatstroke and heat exhaustion and their treatment. Exercise essential to health in the tropics.-Precautions against chills.-To be careful not to expose the body when overheated or fatigued to sudden cold. - To wear suitable garments next the skin day and night.-Prickly heat.-Use of a cholera belt.-Precautions in regard to bathing.Sleep.-Precautions to avoid infection of malaria.

CHAPTER II.

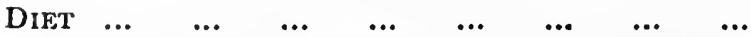

Excess of animal food should be avoided.-Meals. - Necessity for precautions in the selection and preparation of food.-Flies : their contamination of food and drink, and their prevention.-The strictest moderation is required as regards alcoholic drinks.

DRINKING WATER ... $\quad \ldots \quad$...

Personal supervision required for the purification of drinking water,-The water should be boiled.If filtered, kinds of filters that should be used.Treatment of muddy and turbid waters.-Tea and coffee.-Ice- and soda-water. 
viii. Conients

PAGE

CHAPTER III.

Dwelling House ..

A house close to native huts unhealthy.-Site must be dry.-Two-storied houses preferable.-Rooms should be high.-Precautions against erecting a damp house.-Coolness obtained by ventilated air space between the roof and ceiling.-Corrugated iron must be lined with felt or wood or both.Coolest houses are those with interior courtyard.Bathroom.-Tanks to store roof-water.-Servants' quarters.

\section{CHAPTER IV.}

ILNesSes OF THE TROPICS AND THFiR PREVENTION

Prevention of bowel complaints.

Malarial Fever ...

Different types of malarial fever.-General symptoms.-Causation of malarial fever a parasite in the blood.-Manner by which the parasite gains an entrance into the blood for a long time unexplained. - Observations leading up to the explanation.-The Anopheles mosquito proved to be the agent.-Description of the Anopheles and its life-history.-Winged stage.-Egg stage.Larval stage.-Pupal stage.-Mode of infection of the mosquito.-Mode of infection of human beings by the mosquito.-Preventive measures.-Protection of a malarial patient from the bites of mosquitoes.-The protection of healthy people against bites of mosquitoes.-Italian experiments. -British experiments.-Protection of the house. -Mosquito wire screens.-Fumigation.-Living in a house well away from native huts and houses. -Protection of the individual outside the house 
MaLaRIAL FEVER-continued.

at night.-The methods described must be supplemented by destruction of the larvæ and pupæ of mosquitoes.-Breeding places of larvæ and pupæe. -The shortest period of the water life of the mosquito is a little over a week.-Measures to be taken to destroy the larvæ and pupæ.-Emptying of receptacles containing water, and brushing out puddles. - Use of mosquito screens for water reservoirs and cisterns.-Spreading a thin film of oil on the surface of the water.-Filling up the excavations and depressions, and levelling and draining uneven surfaces.-Quinine as a prophylactic during the malarial season.--Sale of quinine at every post office.

\section{Yellow FEVER AND Filariasis} -.. $\quad \cdots \quad \ldots$

Yellow fever.-Prevention of breeding of Stegomyia.-Filariasis.-Measures against mosquitoes will prevent malaria, yellow fever, and filariasis. -Individual effort necessary.-Measures by the local authority also necessary.

ReLAPSING FEVER AND INSECTS

... $\quad \ldots \quad \ldots$

Symptoms of relapsing fever.-Spirochætes the causal agent in the blood.-Modes of transmission. - Habits of the tick and precautions to be taken against it.-Destruction of ticks.-Destruction of bugs.- The different kinds of lice.-Precautions against and destruction of lice. - Insecticide powders.

TryPanosomiasis or Sleeping Sickness ...

History.-Symptoms.-The Glossina palpalis and its habits.-Precautions. 
The Enteric Fevers, or Typhoid and ParaTYPHOID FEVERS

Period of incubation and course of typhoid fever.Causation.-Mode of exit of infection from the body.-Prevention of the spread of typhoid fever. -Destruction of the infectious material immediately it leaves the body all-important.-Modes of dissemination of typhoid fever.-Precautions against typhoid fever.

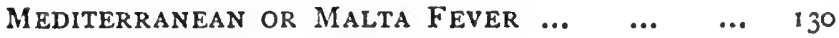
Symptoms.-Prevention.

\section{Cholera}

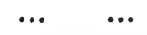$$
\text { (... }
$$$$
\text { -.. }
$$$$
\cdots
$$

Causation.-Symptoms. - A cholera patient not dangerous to others if certain precautions taken. -Immediate treatment necessary.-To prevent spread of the disease.-Precautions.

DYSENTERY ...

Causation.-Symptoms of disease.-Treatment.Prevention.

\section{Plague}

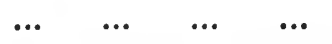

Modes of infection.-Precautions and prevention. .

WORMS

AnCYLOSTOMIASIS

Symptoms.-Modes of infection.-Prevention.

BILHARZIOSIS ... $\quad \cdots$ ... ... ‥

Symptoms.-Modes of infection.-Prevention. 
CHAPTER V.

$\begin{array}{lllllllll}\text { SNAKE-BITE } & \ldots & \ldots & \ldots & \ldots & \ldots & \ldots & \ldots & 158\end{array}$

Vipers.-Colubrines.-Safest to treat all snake-bites as poisonous. - Symptoms. - Treatment. - Precautions to be taken against snakes. - Treatment of stings and bites of insects.-The sand-flea.

\section{CHAPTER VI.}

Wounds

Difference between bleeding from arteries and from veins. - Where to apply pressure to arrest bleeding. - How to apply pressure to arrest bleeding.Treatment of wounds. - Burns and scalds.Sprains.

MEdical EQUipMENT $\begin{array}{lllll}\cdots & \ldots & \ldots & \ldots & \ldots\end{array}$ 



\section{THE MAINTENANCE OF HEALTH IN THE TROPICS.}

\section{CHAPTER I.}

Climate and Personal Precautions.

IT will perhaps be well to begin this handbook by stating what are the regions to which the terms tropical and subtropical apply. The tropical or torrid zone is that part of the earth's surface which extends from the Equator to the north and south parallels of $23^{\circ} 28^{\prime} 40^{\prime \prime}$. The tropic of Cancer is its northern parallel; the tropic of Capricorn is its southern. Between these parallels is the apparent path of the sun, and over some portion of the belt the sun is always vertical. The subtropical zone is a region extending beyond the Zodiac belt to $35^{\circ}$ north and south, and comes under the powerful influence of the sun on its approach to the tropic of Cancer or the tropic of Capricorn. 
The climate of this vast region, embracing some $70^{\circ}$ of the earth's surface, varies greatly. Climate. The torrid zone, as its name implies, has the highest mean temperature, but there is great variation in temperature even within this zone. This variation depends on a number of conditions which it is needless to enter into here. But it may be stated generally that the climate and temperature in the tropical and subtropical regions are governed largely by the amount of humidity in the air and the amount of rain the locality" receives and the situation of the locality, whether it is in the plains near the sea or inland on the high lands. Islands and coast regions possess a more equable temperature than the interior of continents. The abundance of rain and amount of watery vapour in the air in the equatorial regions prevent the temperature reaching those extremes which are to be found farther away from the Equator and in drier regions. The temperature in these equable regions is seldom above $85^{\circ} \mathrm{F}$. or $90^{\circ} \mathrm{F}$. in the shade, but in the drier regions it may be as high as $120^{\circ} \mathrm{F}$. in the 
summer. The climate may be broadly judged of by the kind and nature of the vegetation. The influence of a powerful sun, permanent warmth, great moisture, and equable seasons is displayed in an endless variety of luxuriant vegetation not to be seen in any part of Europe; on the other hand, the influence of a powerful sun, parching winds and a small amount of rain is distinctly unfavourable to vegetation, and large tracts of the country may remain arid and uncultivated. There are many gradations between these two extremes which indicate more or less approximation to moist or dry climates.

A European requires to exercise reasonable care for his health in the tropics.
A European entering the tropics has to be careful in many things, if he is to preserve his health. The environment is so different from that which he has been accustomed to that it requires a certain time before he becomes acclimatized to the new conditions.

Full of the energy begotten of a birthplace in a temperate or cold climate, he is not sensible at first of the great power of the sun, 
and of the great difference of temperature of the air to which he is subjected. $\mathrm{He}$ is accordingly apt to expose himself in a way that with more experience he would never dream of, and to forget to adapt his mode of life to the new conditions. There are rules or axioms which should never be forgotten in the tropics. The first is not to expose oneself to the sun unless the head is well protected; the second is to avoid chills, which may easily be contracted by exposing the body to the cool evening breezes when fatigued or over-heated by exercise, and the third is to avoid as far as possible the infection of malaria.

If attention is paid to these three rules, life in the tropics, even under the most trying conditions, may be as healthy as in temperate regions, always provided that, as at home, the ordinary sanitary canons as regards purity of water and drink, wholesome food, healthy dwellings and personal hygiene are attended to.

There should be no undue exposure to the

Precautions against undue exposure to the sun's rays. sun's rays, especially during the hottest hours of the day, unless well protected. It is 
true that some constitutions appear to be able to withstand any amount of exposure to the sun, just as others are often able apparently to withstand the injurious effect of excessive drinking. Such individuals will go about during the day with an ordinary cap on their head, or even bare-headed. They are exceptions, and their example should on no account be followed. Excessive exposure to the sun, and especially so when the atmosphere is full of moisture, almost invariably produces headache, slight fever, and ultimately a high degree of nervous irritability ending not infrequently in a nervous breakdown. Sometimes it causes sunstroke.

As there is great variation in the heat in the tropics, the following remarks will apply to the hottest regions and to those parts in which the sun and atmospheric conditions are dangerous. The precautions may be modified to suit the circumstances of those localities that enjoy a lower temperature. If duty involves much exposure to the sun in the summer time it is necessary for the head and spine to be thoroughly protected. In India the head is 
protected by wearing a solah topee, which is made of pith. It is light-which is always an important point in any headgear in hot climates. It should be shaped to shield the temples and the nape of the neck, and it should be so ventilated as to permit of a good sirculation of fresh air in the space between the head and the topee. Helmets and topees are often made of felt; these are neater-looking, but they are usually possessed of very little protective power, and should be avoided. Large "Terai" hats, generally with a puggree on them to protect the back of the neck. are preferred in some localities. The newcomer should try no experiments of his own but be guided by the custom of Europeans in the place. If solah topees are generally worn it would be foolish to wear a Terai hat. In places where the glare is great the eyes need protection by wearing neutral-tinted or dark smoke-coloured glasses. The latter are generally the more comfortable. As the spine is sensitive to the sun's rays, a spinal pad fixed in the lining of the coat is an additional protection, especially when out riding or shooting, 
or on the march. The injurious effects of the sun are believed to be caused by the chemical rays rather than by the heat rays. For this reason it is recommended that red, orange or yellow-coloured materials, which do not allow the chemical rays to pass through them, should be used for the lining of the topee and of the spine pad. For the same reason a shirt or vest of one or other of these colours may be worn. Natives of hot climates are fond of these bright colours, and it is possible that they learnt from experience their comfort. Woollen socks should be worn, and when out in the jungle or camping out strong boots with puttees or leggings should also be worn. The latter are protective against snakes, leeches, and insects. Shorts which expose the knees should not be worn in countries swarming with biting flies. They only add to the risk of infection. If compelled to go out during the hottest part of the day in the summer, it is better not to walk; but if this cannot be avoided it is well to be provided with a good large white umbrella, lined with red material, a pair of smoke-coloured 
spectacles, and a broad-brimmed topee. If in a conveyance the hood should always be up. In long journeys the hood is often protected by wetted straw or matting. If in a railway train crossing the plains of India in April and May the tatties need to be conHeat-stroke and stantly kept wet, and much heat-exhaustion relief is afforded by bathing ment. the head when feeling uncomfortable, and by occasionally sipping ice water. Persons suffering from exhaustion or ill-health should not travel during the extremely hot season, for at this time, though there may be no direct exposure to the sun, the high temperature in the shade-especially if the air is stagnant and impure-may produce sunstroke or heat-stroke, or heat-exhaustion. Sunstroke or heat-stroke in its milder forms is characterized by giddiness and faintness, headache, fever, intolerance of light, and vomiting. Its graver forms have more pronounced symptoms, in which the head is much congested, the face is flushed, the breathing is difficult, the skin feels hot, the temperature is high, and the patient becomes unconscious. Treatment 
should be immediate, and until the doctor arrives the sufferer should be taken to a cool; shady place, the clothes should be loosened, and ice and cold water should be applied freely to the head and back of the neck. On the other hand, in heat-exhaustion the patient becomes pale and giddy, falls to the ground, and is almost pulseless and very cold. The patient has fainted. The treatment is the same as for an ordinary fainting fit. Lay the patient on his or her back in a cool and airy place, loosen the clothes, apply ammonia or smelling salts to the nostrils, and dash a little water on the face and neck.

On the other hand, while a warning is necessary to the new arrival against undue exposure

Exercise essential to health in is required not to lead a too the tropics. sedentary life and remain too much indoors. Exercise and an open-air life are essential to health in the tropics, and can readily be obtained all the year round, except during the hottest hours of the day. The period of prohibitive heat during the day varies much in different places, being longer in some 
places than in others. It also varies according to the season of the year. Exercise should be regular and short of fatigue. The people who enjoy the best health are generally those who are fond of riding and outdoor exercise, such as lawn tennis, rackets, golf, bicycling, and other similar pastimes. Walking is also a good form of exercise. Care has to be taken that the exercise shall not be carried to excess. Over-fatigue is apt to bring on languor and fever, which neutralize the benefits derived from exercise.

Precautions against chill are particularly necessary on account of the sensitive state of the skin, which is peculiarly susceptible to

Precautions external impressions of cold.

against chills. Chill holds a very important place as the exciting cause of disease in warm climates. The skin is more active and sensitive in a hot climate than in a cold. There is a larger supply of blood at the surface, and the evaporation and perspiration from the body are greater. A sudden check to the transudation from the skin, or to the perspiration, is apt to cause disturbances of the liver, bowels, or other 
internal organs. It is therefore advisable as far as possible to prevent the skin from being subjected to great changes of temperature. This is best effected by not exposing the body when overheated to sudden cold, and by wearing suitable garments next to the skin which will keep the body at a uniform temperature. Wettings are liable to cause chills, and these chills may cause an attack of malarial fever in anyone who has suffered from malarial fever before. In travelling in the rainy season a macintosh and india-rubber boots should form a part of the equipment.

Violent exercise, followed by a drive in the evening before changing the clothes, may be the cause of a severe attack of diarrhœa, inflammatory dysentery, or congestion of the liver. After lawn tennis or golf, a thick overcoat, sweater or cloak should be immediately put To be careful not on, and the clothes should be to expose the body when oyerchanged as soon as possible. heated or fatigued The sitting in a draught, or to sudden cold. under a punkah, or opening one's jacket to enjoy the coolness of the evening breeze whilst in a state of perspiration or 
exhaustion is to be avoided. It is a precaution which is at first not easy to remember, but the enjoyment, though ever so pleasant, is fraught with risks. When heated or fatigued, a cold bath ought never to be taken; a warm bath or a good rub down with a rough towel, or both, is more refreshing and is safe. At night in the hot weather there is special liability to chills. Then the body is apt to be drenched with a profuse perspiration, and if the night clothing is not thoroughly absorbent the result is apt to be a chill.

To prevent the effects of a chill developing when unavoidably exposed to one, it is advisable to take a hot bath, go to bed, take a warm drink, an aperient and, in. malarial subjects, ten grains of quinine.

For comfort and for health, the undergarments in warm climates ought to be loosefitting in order that there shall be a free To xear suitable circulation of air between them garments next the skinday and the surface of the skin night.

to carry off the hot vapours. They ought also to be made of material to prevent rapid evaporation and the chilling 
effect which this is liable to produce. Wool answers these requirements better than any other material. Wool is pleasanter and healthier than either cotton or linen, because it preserves an equable temperature around the body, and it is cooler because it permits of a healthy interchange of the gases on the surface of the body and atmospheric air. Silk has similar properties to wool; cotton and linen, on the other hand, do not absorb moisture in the same manner as wool without chilling the body, and they are only half as permeable to air ; hence they are less comfortable to wear, and are not protective against chill induced by rain, exposure to a cold wind, exercise or other conditions. Cotton, however, when loosely woven gains in absorbent power, and when mixed with either wool or silk is very comfortable.

It is easier to take cold in a warm climate, owing to the sensitive condition of the skin, than in cold climates where ample protection in the shape of warm clothing is provided, and the skin is not nearly so sensitive. The material to be used for under-garments should 
be of the finest. It should be light, porous, and loose. Coarse wool irritates the skin

Prickly heat. and conduces to prickly heat. Prickly heat is one of the annoyances of the tropics. It is a skin eruption and is extremely itchy, but scratching only tends to make the irritation worse. It is due to excessive perspiration irritating the skin. For its avoidance the under-garments should not be irritating, and should be changed frequently. The bath should be taken regularly, and no irritating soap should be used. To allay irritation a powder consisting of equal parts of boracic acid and of starch is useful to sprinkle over the part affected after the bath and thorough drying. For those persons who cannot wear wool silk is a good substitute, or a mixture of wool and cotton or "Anglo-Indian gauze" which is a mixture of wool and silk. Cellular cloth is sometimes worn with comfort, for though its fabric is of cotton it is so made as to allow of evaporation.

A cholera belt, which is the name given to a knitted belt, placed round the body below the 
Use of a waist, and which is best made cholera belt. of Jaeger wool, should always be worn both by men and women. One should be worn during the day and another at night. It protects parts particularly susceptible to cold. In order that the cholera belt shall not shift its position it is best to have it attached to the pyjamas or under drawers. As long as the fundamental principle of wearing loose woollen or silken garments next the skin is practised the kind of upper garments worn is of small moment and varies much in different places. They should be loose and light in weight. The colour should be white, grey, or khaki, as these absorb the sun's rays least. Dark colours are not advisable except in the evening, and even then white is preferable. In the winter months, in the highlands of East Africa in hill stations, and wherever cold winds prevail at certain seasons of year, as in Egypt, warm European clothing requires to be worn. Sleeping suits and garments should always be of fine flannel or a mixture of wool and silk. When camping out a Jaeger sleeping sack, or one made out of ordinary blanket, is a great 
comfort and is a special safeguard against chill. During the hot weather and rains the body perspires on the slightest exertion, and it is necessary to change the clothes several times a day, and especially so before sundown, Damp clothes require to be regularly aired and dried before being put on again, and in the rains they should always be dried every night.

$A$ warm bath after exercise or exposure to inclement weather is a means of avoiding a chill, and is at the same time refreshing.

Europeans sometimes get into ill-health by continuing in the tropics their cold bath, to

Precautions

in regard to bathing. which they were accustomed in colder climates. The cold is apt to produce, especially when the body is overheated or fatigued, congestion of the internal organs. For healthy Europeans the tepid bath is, as a rule, not only the safer, but the more refreshing. For those suffering from bowel complaints or disorder of the liver the warm bath only should be taken, and the cold or even tepid bath is unsafe. In travelling, especially when water 
for bathing has to be taken from ponds or pools or water-holes, or where the water is muddy and obtained from rivers or stagnant pools, the bathing water should be boiled as it may contain the larvæ of Bilharzia or Ancylostomes that have the power of penetrating the skin and causing painful and serious worm diseases.

An important point in securing refreshing sleep and in maintaining health in the tropics is the cultivation of regular habits and hours in going to bed. Late hours Sleep. are most unsuitable, and if kept for any length of time are likely to induce a habit of sleeplessness not conducive to health. During sleep, especially in the early hours, the body is particularly liable to chill unless well protected by woollen garments.

The methods to be adopted for the avoidance of infection of malaria involve for their

Precautions to axoid infection of malaria. due understanding a longer description of malaria and of the manner in which the mosquito acts as the carrier of the infection. As a preliminary warning it may be well to state 
that no one should go to a warm climate without being provided with a pair of mosquito boots and a good-sized mosquito net of a mesh of twenty strands to the inch. The net is useful in the ports at which the vessel may stay before arrival at its destination, and especially in the passage up the rivers, and it is always useful on arrival. Fine muslin is even more protective than mosquito netting, as it excludes sand-flies as well, but on sultry nights its use is felt by some to be more oppressive than mosquito netting; when, however, there is good ventilation in the room the muslin is to be preferred.

The mosquito curtains of the bed should always be let down and fixed well before sundown in order that they may exclude from the bed any mosquitoes, which at that time enter the room or emerge from their hiding places in the room. They should not be let down so as to hang to the floor, as mosquitoes may hide under the bed; but they should be tucked under the mattress. The lower part of the mosquito curtains for a foot or more should be made of calico, and should be double so as to 
shield from bites should the limbs come in contact with it during sleep. In some countries sand-flies are a pest and most troublesome to the sleeper. Protection is not afforded by the ordinary mosquito curtain, a finer mosquito net with thirty strands to the inch being required.

Mosquito boots, which are of the Wellington type but made of soft leather, are useful at sundown and very comfortable to wear during the evening. They protect the feet, ankles and lower part of the legs, which are particular objects of attack by mosquitoes. 


\section{CHAPTER II.}

\section{DiET.} food should be aroided.
Excess of animal

As regards food, the European has to avoid the tendency to over-indulgence. A hot climate throws a strain on the liver in getting rid of effete matters, and it is not a good thing to add to that strain by eating too much animal food. Moreover, the inferior quality of the beef, mutton, fowl, and goat's flesh which is available is liable, if not taken in moderation, to disturb the digestive system. Happily the days of heavy luncheons and heavy drinks in the middle of the day are, for the most part, over, and with them have gone many of the diseases which were attributed to climate. On the other hand, it is unwise to be too sparing in one's diet, especially if there is a fair amount of work to be done. A moderate reduction in the amount of animal food and the substitution 
of a more liberal allowance of vegetable food, including cereals and fruits, will be found Meals. generally to be most suitable. It is well to conform at once to the custom of Europeans in the country, which is to take a light breakfast, or Chota Hazaree, in the early morning, about 6 a.m. or 6.30 a.m., just before going out. This breakfast consists of tea, coffee, or cocoa, with bread and butter or toast or biscuit, and fruits of the season. If the work of the morning is to be hard an egg will be a good addition. A more substantial breakfast is taken about II.3O a.m. or 12 noon, after a bath and the full morning's work. It is usually similar to a substantial English lunch, with some preparation of rice and fruits added. Some light refreshment is taken at tea-time, and there is the dinner at night similar in its menu to the breakfast at noon. Those whose work is indoors usually have a lighter breakfast earlier, and a light lunch about 2 p.m. A simple fare is the best, made dishes and rechauffés are to be avoided, as they are likely to cause indigestion. Meat three times a day will 
sooner or later do harm. Except in large towns there is not much choice as to the Necessity for premeats obtainable.

cautions in the

Pork should be shunned at selection and preparation of food.

all times, as it is liable to be infested with parasites, the pig being a foul feeder. Beef also has to be carefully selected and well cooked, otherwise, owing to containing parasites, it may be the cause of tapeworm. Beef having small bladder-like substances in its flesh should not be eaten. All supplies of meat, fish, vegetables, and fruits should be inspected when they are brought by the cook from the market. Fish should always be fresh, as indicated by the pink appearance of the gills. Tainted or putrid fish is dangerous, and is apt to give rise to poisoning and violent diarrhœa. Oysters should be avoided unless they are cooked, for there is always a risk of contracting typhoid fever from them. Fruits should be eaten in the morning and for the mid-day breakfast; but it is better to abstain from them at night. They should be ripe and sound. Watercress, salads, and 
raw vegetables should be eschewed unless they are specially prepared and cleaned by a very reliable person, who will wash them thoroughly in water which has been previously boiled. Raw vegetables take up germs and the ova of parasites of disease from the water or soil from which they are gathered. In this way uncooked vegetables, unless properly cleaned, are apt to produce typhoid fever, dysentery, and intestinal worms. Milk in tea or coffee or as a drink requires special care. It is best always to boil the milk. To drink milk unboiled in the tropics is always dangerous. Boiled milk is more digestible than unboiled milk, and as no germs can withstand boiling it is certain to be safe. In the tropics the addition to the milk of water from dirty ponds, tanks, and wells is a common practice, and as these ponds, tanks and wells contain, as a rule, germs of disease or ova of parasites, the drinking of uncooked milk is unsafe and dangerous. Even if water be not added to the milk, the cowshed and milk utensils are so dirty and the surroundings so insanitary that the risks of the milk becoming infected with disease germs or 
parasites is always present. Similar precautions should be taken in regard to goat's milk. Perhaps the simplest and safest form in which milk can be taken in tropical countries is the condensed variety.

After the milk is boiled it should be protected from dust and flies, and insects, until required, by covering with muslin.

It is not enough to inspect the food as it comes from the market and insist on proper cooking; attention to the

Regular inspection of the kitchen and surroundings necessary. kitchen is a necessary part of the rules for retaining health in the tropics. The kitchen should be visited regularly once or twice a week to ensure cleanliness, and the cooking utensils, ice-box, safe and cupboards thoroughly inspected as to their cleanliness and condition. Dishes should be washed with boiled water. When the pots require repair the native often solders them with lead instead of tin. This should not be allowed, for it is likely to cause poisoning. Food ought not to be prepared in either leaden or copper vessels. It should always be protected by wire gauze dish covers, which should be kept scrupulously clean. No 
kitchen should be without its meat safe and icebox. The servants' latrines should also be regularly inspected to see that they are kept in a clean and sanitary condition and are not harbouring flies.

Flies in the kitchen or house are an abomination. They are foul feeders, and after feeding Flies, their con- on filth or the latrine contamination of food tents they will migrate to the and prevention.

kitchen, and if the food or milk there is unprotected they will smear the food or contaminate the milk with the filth on their bodies. In this manner they may spread infection. If flies are present their breeding-place should be searched for and removed. They breed in decomposing matter, animal or vegetable, in house refuse, straw, decaying vegetables and fruits, bad meat, decomposed grain, and in manure. Accumulations of filth and refuse should therefore not be allowed; no refuse should be allowed to be thrown on to the ground, but be placed in a covered bin or kerosene tin, and removed daily and burnt. If outside the premises there are some rubbish or manure heaps that cannot be removed, kerosene, turpentine, or creasote, or a mixture 
of these, should be poured or sprayed on the heaps with the object of destroying the larvæ, and preventing the flies laying their eggs on these heaps. In the event of flies still invading the kitchen it should be rendered fly-proof by mosquito wire netting. Latrines also should be similarly rendered fly- and mosquito-proof.

A great improvement has taken place in the custom of residents in the tropics with The strictest reference to the drinking of moderation is re- alcoholic stimulants. Exhausalcoholio drinks. tion is frequently felt in hot climates after exposure to the sun and after months of living in a kind of Russian bath caused by the high temperature of the air, the saturation of the air with moisture and the copious perspiration which the body is in under these conditions. In the early days this feeling of exhaustion used to be counteracted by the partaking of many pegs of brandy or whisky. The term peg, implying a peg in one's coffin, represented even then the conception of the general injurious results which followed from this practice. Alcohol in the tropics has a much more injurious effect on the liver and on 
the system generally than it has in a temperate climate, and in the days when nipping and pegging were in vogue at all times of the day much illness was attributed to climate which was really caused by this pernicious habit. Many cases of sunstroke have been intimately connected with exposure to the sun after drinking alcohol. All alcoholic drinks should be shunned until the sun goes down. Young people going to the tropics will enjoy far better health and be better workers if abstainers. It is wiser to follow the customs of the natives of the country, who as a rule drink tea, coffee, water, or sherbet. It is only when long years of residence in the tropics causes torpidity and impairment of digestion that, for Europeans, a moderate use of alcohol at dinner is of benefit. It should be taken in the smallest quantities: $2 \mathrm{oz}$. of whisky or a pint of the lighter wines, such as claret or hock, should be the limit. Even these quantities for some persons are excessive.

Drinking Water.

It is impossible to be too particular about the purity of the water which is drunk in the 
tropics, and whether travelling or resident, Personal supervi- its purification should be persion required for sonally supervised. The cusdrinking water. toms of the natives are such that there is no security against contamination, whether it be river water, well water, or water stored in tanks. The same remarks apply to the condition of the vessels in which the water is collected. All waters should be looked on with suspicion, and should be subjected to filtration or boiling, or both. The diseases caused by drinking polluted water in the tropics are too many and too serious for anyone to run the risk. Sewage-contaminated and impure water is the medium for the spread of cholera, dysentery, enteric fever, diarrhœa, intestinal worms producing poverty of blood (ancylostomiasis), guinea-worms, and painful affections of the urinary system (bilharzia disease).

Even in the larger towns, where a public water supply is provided, though there is not The water should the same necessity as in other be boiled. parts of the country, where water is liable to all forms of pollution, yet it 
is still advisable to boil and cool the drinking water. After boiling, care must be taken to store the water in a clean vessel, and to protect it from any contamination in the process of cooling. The vessel should be covered by clean muslin. The cooling may be effected by wrapping a wet cloth around the vessel and exposing it to the air.

Next to boiling, filtration is the only other fairly safe method of treating the water before If filtered, kinds of filters that boiling. The best filters for should be used.

this purpose are the Doulton and the Pasteur-Chamberland filters, of which there are several kinds, portable and convenient in size. The Berkefeld is also a good useful filter. Other kinds, unless they are proved to be germ-proof, should be discarded, for they are difficult to keep clean, and instead of purifying not infrequently add their own impurities to the water. The only exception to this is when dealing with the muddy waters of rivers or slimy waters of ponds. These will clog up the pores of a Doulton or a Pasteur-Chamberland or Berkefeld filter, and render them useless in 
a very short time. Under these circumstances a rough filtration to get rid of the suspended matter and mud in the water is necessary before attempting to pass it through a germproof filter.

For this rough filtration charcoal, asbestos, magnetic carbide, spongy iron, polarite sand or other similar filters can be used. Even these, however, must be regularly cleaned, and should be boiled at least once a fortnight. The Doulton and the Pasteur-Chamberland filters are composed of a special porcelain-like material, shaped in the form of slender tubes or candles, which are hollow. Each tube forms a filter in itself, and can be used as such if there is sufficient pressure of water.

The Berkefeld filter is on the same principle. It consists of diatomaceous earth made into a thick instead of a thin cylinder, and allows of water being filtered more rapidly. It has the disadvantage, however, of being more brittle than either the Doulton or the PasteurChamberland. Figs. 1 and 2 show two of Berkefeld's filters. Of course, the greater the pressure of the water the faster the water 
passes through the tubes. Care, however, has to be taken that the tubes are protected, for they are easily broken. For this purpose single tubes are encased in metal or enclosed

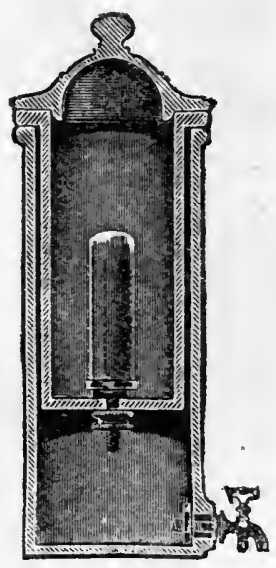

FIG. I.

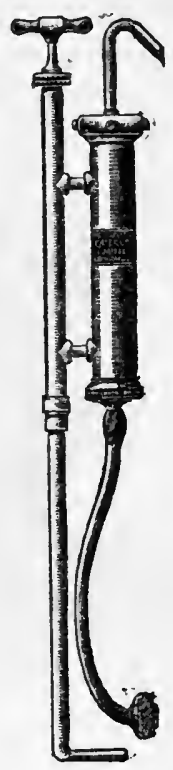

FIG. 2.

in a glass jacket. The filter thus shielded may be fixed on the water taps of a house, or for travelling may be attached to a hand-pump, as in fig. 2 , or in a house it may be 
pumped from a well through the filter as in fig. 3. The water passes through the Doulton, Pasteur-Chamberland and Berkefeld filters from without inwards, and much more water is given by the latter filter than the others

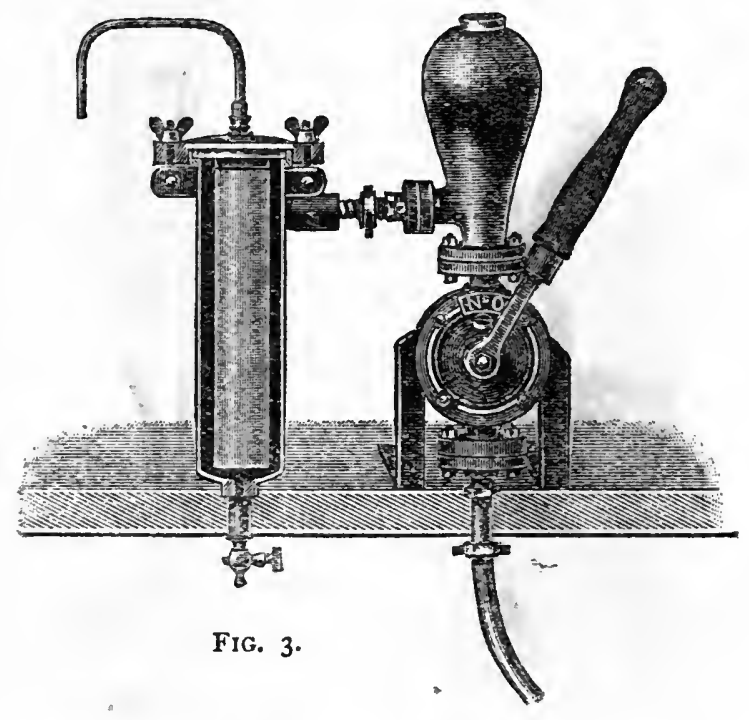

under the same pressure. As water, even under pressure, passes very slowly through a single tube, a number of tubes are placed in one filter to secure a quicker and larger supply of water.

On a larger scale an installation of tubes 
may be used to filter the water direct from a well, or from a river, or any reservoir of water.

The special appliances belonging to these large filters supply the requisite pressure for the filters.

The filter candles should be cleansed by brushing off the material which has collected on them, and then boiling or baking them for an hour. This should be done once a week. If the water to be filtered has much suspended matter the brushing may require to be more frequent, but there is no need of repeating the boiling or baking.

Other filters of the same type are on the market, and Doulton makes an excellent filter, combining a manganous carbon filter and a germ-intercepting filter of natural stone, which avoids the necessity of having two different kinds of filters when dealing with muddy water.

When there is no rough filter to clear a muddy water, or the filter is not effective, a

Treatment of preliminary addition of alum, muddy and turbid in the proportion of $6 \mathrm{gr}$. yraters.

to every gallon of water, will in a short time clear the fluid, the impurities 
gradually falling to the bottom of the vessel. The clarified water can then be decanted, filtered and boiled or only boiled. If the water is boiled first and then filtered there may be a danger of the boiled water becoming contaminated unless care is taken. When travelling, a quantity of permanganate of potash in crystals is always a very useful chemical to be provided with, in addition to alum. It is particularly useful in getting rid of the disgreeable smell of some waters. It possesses the power of destroying organic matter, and thus rendering water more drinkable. A few grains of permanganate of potash added to a vessel of dirty water produces a pink tinge which gradually disappears. The pink tinge will disappear more quickly when the water is heated. If the process of alternately adding a few grains of the permanganate and heating is continued until a pinkish tinge remains for ten minutes, much of the organic matter is destroyed, and the water can then be boiled and cooled.

If personal supervision cannot be exercised over the purification of the drinking water, it Tea and coffee. is better always to drink tea 
or coffee, toast and water, lemon decoction, rice water or barley water rather than water. These being all made with water which has been subjected to boiling, are free of living germs of infective diseases. Care, however, must be taken that the cooling and storage of these drinks do not expose them to contamination.

In using ice- or soda-water, only supplies from the most unimpeachable sources should Ice- and soda- be employed, Either of these water. obtained from native sources are generally dangerous. Soda-water kept for a fortnight appears to be safer than fresh sodawater if the source is doubtful.

Iced drinks should only be taken sparingly, for in excess they tend to weaken the digestive processes, which are already somewhat impaired by climatic conditions. Similarly, drinking large quantities of fluid, even if only water, should be avoided. Excess of fluid is a cause of dilated stomach and dyspepsia in Europeans in the tropics. On the other hand, if there has been much perspiration owing to great heat a sufficient quantity of water is needed to supply the waste. 


\section{CHAPTER III.}

\section{DWELLING HOUSE.}

THERE are certain important points in connection with dwelling houses in the tropics

A house close to native huts un- mind when either leasing or healthy. which should be borne in building a house. First, the houses should not be surrounded by nor close to native huts. Native children are seldom not infected with malaria, and hence living in a dwelling house in this position increases the risk of infection from that disease. The mosquitoes carry the infection from the native children to the European. For this reason a dwelling house among native huts is an unhealthy house, apart from the fact that it will also always be in the midst of other insanitary conditions.

Secondly, the house should not be near to site must be dry. stagnant water, nor situated 
on a low-lying site where the water does not readily drain away, nor exposed unsheltered to the chilling air in a ravine. An elevated and dry site on sloping ground, but not in a hollow, should always be chosen as far as possible. Even in a hilly country a site may be unhealthy if in a hollow surrounded by hills which impede ventilation and favour stagnation of air, or close to a stream breeding mosquitoes. No house should be erected on the side of a hill exposed to the winds from a marsh. If no other site is possible it must be a mosquito-proof house.

Thirdly, the rooms of the house should always be raised well above the surface of

Two-storied the ground. A two-storied houses preferable. house in which the sleeping apartments are upstairs is likely to be a more healthy house than that which is single-storied.

Rooms should

Fourthly, the rooms should be high. be high, and there should be an air space between the ceiling and the roof. Fifthly, there should always be a verandah of $10 \mathrm{ft}$. to $\mathrm{I} 2 \mathrm{ft}$. ; and sixthly, the servants' quarters should be well away from the house, 
but within the compound, which should always be large, in order that the house shall secure around it a free circulation of air.

\section{Precautions}

In building a house or hut against erecting the foundations require a cona damp house. crete or other impermeable basement, to exclude damp and impure ground air. Raising the house on pillars and arches in addition effects this even more thoroughly by permitting free ventilation underneath. The walls will otherwise become damp by drawing up moisture from the soil. An ordinary brick will hold about 16 oz. of water. To prevent this saturation of the lower wall of a house a damp-proof course is not only required in the foundations but in the wall for at least a foot above the surface of the ground, and below the lowest timbers or floor supports. The damp-proof course can be made of any impermeable material which is at hand, and which is suitable for a building. If nothing better can be obtained, tarred bricks are useful. The bricks are first heated and then plunged into a bath of boiling tar, and then rolled in dry sand. 
The walls should also be protected as much as possible by overhanging eaves.

Every house should be surrounded by a well-constructed drain to receive rain-water from the roof if there are gutters and rainwater pipes, and to carry off the water streaming down the walls during the rains, and prevent soakage causing dampness of the walls, or the formation of puddles which would harbour mosquitoes. It should also have a space of $10 \mathrm{ft}$. or $12 \mathrm{ft}$. which is paved, tiled or well consolidated with vitrified brick, and which is sloped away from the house. A belt of sharp gravel beyond this is an obstacle to snakes. Outside the gravel short grass, Bahama, French or Indian grass is the most suitable and most healthy kind of vegetation to be near a house. Trees ought not to be so close as to obstruct the ventilation or tend to make the house damp. Bamboo and banana trees should never be planted near a house as they favour the breeding of larvæ of mosquitoes in the water they contain.

Coolness is obtained by having double ceilings and double roofs. The air space between 
Coolness obtained by centilated aix space between the roof and ceiling.

the ceiling and the roof interposes a layer of air and lessens the radiant effect of the heat from the roof to the room. The air space should, however, have conmunications with the outer air, so as to secure good ventilation, but these openings should be protected by wire gauze, to prevent the entrance of rats, bats and snakes.

Low ceilings always render a room oppressively hot, and should therefore be avoided.

The materials used for the building of a house will depend on what is obtainable in the

Corrugated iron must be lined with felt or wood or both. district. Stone or brick is, of course, the best, but wood and corrugated iron make comfortable houses. If corrugated iron is used it should be lined with felt if obtainable, and close boarding. Without these, whether used for the whole structure of the house or only for the roof, corrugated iron will be found to be unsuitable. During the intense heat it will not be sufficiently protective, and during the cooler weather it will not be warm enough. Roofs of bamboo frames with local 
thatching of palm leaves, long grass, \&c., are cool, but they harbour vermin.

The coolest kind of houses are those built with a courtyard in the centre. They allow of Coolest houses are every room being freely ventithose with in- lated, and if the courtyard is terior courtyard. covered at the top with mosquito wire netting it is a pleasant place to sit in the afternoon and evening. Whether built with a courtyard or not, every house in the tropics should have a good-sized verandah, either all round or on the most sunny side. It adds to the coolness and comfort of the house, and also protects the rooms against the direct solar rays, and against beating rain. If the verandahs are going to be used for dining in or sitting in of an evening, they ought, if in a malarious district, to be protected by wire gauze netting to prevent mosquitoes gaining access to them.

The bathroom may be either detached from the house and approached by a separate verandah, or it may be a

Bathroom. separate room of the house approached from the verandah. In either case 
it is usual for it to contain a commode or an earth closet. In the event of a commode being employed it is taken away and emptied immediately after use into a small covered receptacle kept in a special shed in the compound. The commode should be disinfected. The contents of this receptacle are then either taken away by the local authorities daily or they are buried in the garden. This burial must be done with care, and the surface properly levelled, so that no puddles may be formed during the rainy weather. An earth or sawdust closet may be used. The bathroom should be mosquito protected by wire gauze in its windows and other openings.

If water is not obtainable from a well, or if obtainable is not good, it will be necessary to Tanks to store collect rain-water for drinkroof-yater. ing purposes from the roof. This always presupposes a roof other than thatch. If water is collected from the roof it is preferable to store it in galvanized iron tanks or in masonry tanks, and these should be large. Wooden tubs and vats should not be used. The tanks should be at the side 
of the house, and not underground, and they should always be covered with a lid, between which and the water should be a mosquito wire netting to protect the stored water from mosquitoes and insects, or the cover should have inset into it wire netting. The inlet pipes from the roof to the tank and the overflow pipe from the tank should be protected with the finest copper wire gauze netting, of at least 100 strands to the cubic inch. They should be cleaned regularly before the rains. The first water falling from the roof should be discarded, as it brings with it the impurities which have collected on the roof during the dry weather.

The outhouses and servants' quarters and latrines should be well away from the house. Servants' quarters. The kitchen only should be near, and if possible connected by a covered passage. The same principle of building to secure dryness, drainage, coolness and cleanliness apply to them. While building it is just as easy to construct the servants' quarters of the same material as the house, but if this is impossible, mud huts raised on 
a good concrete plinth, if properly lighted and ventilated, make comfortable dwellings. Servants, unless kept under strict supervision, throw all sorts of rubbish out on the back premises, amongst which will be jam tins, meat tins, bottles, broken crockery, and other articles capable of holding water in them during the rains. They also keep exposed various receptacles containing water in them. These conditions are excellent for the breeding of mosquitoes. Inspection of the premises should be made twice a week with the object of having receptacles containing water emptied and the tins, bottles, and other articles either removed by the scavenger or buried. 


\section{CHAPTER IV.}

\section{ILLNESSES OF THE TROPICS AND THEIR Prevention.}

It would be impossible to deal with the numerous diseases of the tropics in a hand-

Prevention of book such as this. It may bowel complaints. generally be said, however, that if the purity of the drinking water and milk be secured, the wholesomeness and cleanliness of food attended to and chills are avoided, digestive troubles and bowel complaints, to which there is much tendency in the tropics, and which form, next to malaria, the most frequent cause of ill-health, will as a rule be prevented. The rules, as will have been noted from what has already been stated, are simple, and can be carried out easily by anyone. There are certain special diseases, however, which are preventable, which it is desirable to say something more about. These are malaria, 
yellow fever, typhoid fever, relapsing fever, dysentery, cholera, plague, worm disease, and diseases of the liver.

\section{Malarial Fever.}

Malarial fever is perhaps the most important disease of the tropics. It is widely prevalent, it causes many deaths, invalids in large numbers, and weakens the vital powers to such a degree that the sufferer from malaria is peculiarly liable to be attacked by other diseases.

There are several forms of the disease. In one the fever attacks come on regularly every Different types of twenty-four hours, with an inmalarial fexer. terval of ten or twelve hours of freedom from fever; in another they occur every forty-eight hours, with one day or less of freedom intervening between the attacks; and in a third they come on every seventy-two hours, with two days of natural temperature between. These types may vary to some extent, so that the kind of fever represented is only recognized by the physician. The symptoms also vary, but in general each attack is 
distinguished by a cold stage, a hot stage, and a sweating stage. The cold stage may last General from a few minutes to two symptoms. or three hours. The patient begins to feel cold, and seeks warmth by extra clothing, or exposure to the sun; he then shivers, sometimes but slightly, at other times violently. $\mathrm{He}$ has headache, pains in the limbs and loins, is thirsty, and vomits. After this stage has continued for some time, and no amount of clothing makes the patient feel warm, transitory flushes alternate with the shivering or feeling of chilliness, the feeling of cold diminishes, and then the face becomes flushed, the skin hot and dry, the pulse strong and rapid, the headache increases, the vomiting may become more distressing, and there may be delirium and, in children, convulsions. The temperature if taken will be found to be ${ }_{10} 3^{\circ} \mathrm{F}$. or even higher. This is the hot stage, and may last from two to eight hours or longer. It is followed by the sweating stage, in which the patient perspires profusely, the feverish symptoms subside, the headache passes off, the thirst lessens, and the patient, exhausted, 
falls into a sleep, from which he awakens free from fever. This freedom from fever continues until the next attack is due.

The disease in its several forms is caused by a minute parasite, which gains an entrance into

Causation of malarial fexer a parasite in the blood. the body and lives in the blood of the patient. The blood is made up of red and white corpuscles floating in a clear fluid. This parasite, which was discovered by Laveran, a French physician, in 1880 , attacks the red corpuscles of the blood and destroys them, and were it not for the natural resisting powers of the body, which fight against the parasite and its poison, and for the fact that the parasite is affected by medical treatment, the patient would never recover. When the parasite enters the red corpuscle of the blood, it is comparatively small, but it soon undergoes changes, at the expense of the red blood corpuscle; it increases in size and occupies a considerable proportion of the corpuscle. It then becomes segmented or rosetted, each segment acquiring a spherical form. Finally, the corpuscle breaks down, and allows the segments or spores to escape into 
the blood-stream. Each spore being free, is now ready to attack another red corpuscle, to undergo the same development, repeat the cycle, and discharge another brood into the blood-stream. It is when the young spores of the parasite become free in the blood that they are open to attack. Then there may suddenly appear on the scene and in a state of great activity certain white corpuscles that rush on the young brood of parasites, attack, absorb and digest them. A similar destruction of parasites goes on in the liver, spleen and marrow. In addition to the young spores of the parasite there appear in due course in the blood round and crescent-looking bodies which do not undergo segmentation.

Until a few years ago no explanation could be given as to the manner in which the Manner by which parasite gained an entrance the parasite gains into the blood. There were an entrance into general views of its being long time unex- taken into the system by the plained.

lungs from the air, or by the stomach from swallowing water infected by the malarial parasite. These views have, however, 
proved to be wrong, and it remained for Sir Patrick Manson to direct investigation into the true channels by which infection is brought about. It had been noticed that when the fever continued for a few days that the parasite, instead of breaking up into spores, in some of the corpuscles formed a crescentic body; that this crescentic body, which seemed to be a maturer form of the parasite, when removed from the blood-vessel, gradually assumed a spherical form, threw out from its circumference several whip-like or thread-like projections, which wriggled actively and then became detached and free.

Sir Patrick Manson, watching these changes and pondering over them, came to the con-

Observations clusion that these flagellate leading up to the bodies were the first phase of explanation.

a separate existence of the malarial parasite outside the human body, and for that existence the malarial parasite required a blood-sucking insect, such as the mosquito, to remove it from the circulation of the blood, and then to act as a host for it to develop in, or, in other words, that the parasite, like others of the 
same class, had a further development in some other host, probably an insect, and that that insect was the mosquito. The hypothesis met with a good deal of ridicule at first, but Major (now Lieutenant-Colonel) Sir Ronald Ross, a medical man in the Indian Medical Service, set himself the task of investigating the truth of Sir Patrick Manson's theory. Sir Ronald Ross was soon able to show from experiments with birds suffering from malarial fever that mosquitoes were the intermediate host, and that Sir Patrick Manson was right in his views. Sir Ronald Ross proved that when a certain kind of mosquito bit these malariainfected birds the mature malarial parasites contained in their blood were sucked up and swallowed, and were found in the stomach of the mosquito. There the mature forms soon underwent a change. Some threw out whiplike, wriggling processes, others small protuberances, and by the union of these an egg-cell was formed. This egg-cell, first assuming a worm-like shape, bored its way through the stomach wall of the mosquito, then it changed its shape and became round, and increased much 
in size. After this changes were noticed to take place inside the cell, and finally countless needleshaped spores or germs were seen in the interior. The cell when mature burst, and the spores escaped into the different organs of the body of the mosquito. Some of these needle-shaped spores found their way into the salivary gland of the mosquito, which is connected by a duct with the proboscis of the insect, and in this way were transferred to the blood of healthy birds which were bitten by these mosquitoes. Sir Ronald Ross was able to show the whole process from the beginning to the end. The process takes about eight days for all its stages in the mosquito, and he was able to give birds malarial fever by getting infected mosquitoes to bite them. These investigations thus ended in the great and farreaching discovery of a separate life-cycle of the malarial parasite in its various stages of development in the mosquito, and the demonstration of the exact manner in which an infected mosquito could spread malaria. The mystery was solved. The two cycles of life of the malarial parasite, the one in man and 


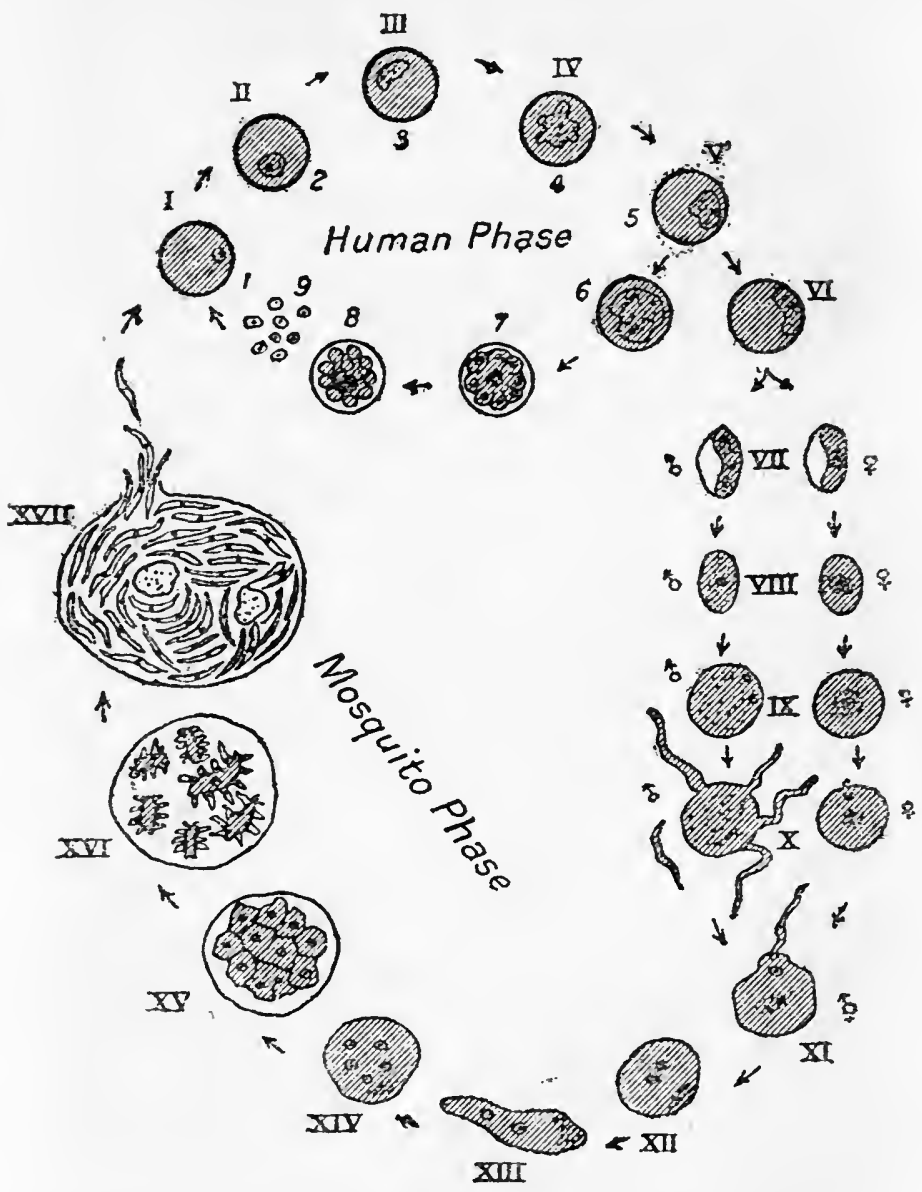

FIG. 4.-The malarial parasite, showing the double cycle of life$I$ to 9 in man; vii to xvii in the mosquito. $\delta$, male; $q$, female. 
the other in the mosquito, are shown in fig. 4 . It is only the female mosquito that bites. The male is a harmless creature.

It was no long step from this complete demonstration of the part which the mosquito The Anopheles plays in causing the malarial mosquito proxed fever of birds to the proof of to be the agent. its rôle in the production of malarial fever in man. Grassi, an Italian naturalist, showed that among the many different kinds of mosquitoes in Italy, one kind was always found in malarial districts. This was the Anopheles, Acting on this information, Bignami, an Italian physician, determined to test the effect of the bite of mosquitoes of the Anopheles kind, brought from a malarious district, on a healthy man. A man who had volunteered on a previous occasion for a similar experiment, which had failed, again offered himself. This time the experiment succeeded, with the result that the Anopheles infected him with the same type of malarial fever as that prevailing in the district from which the Anopheles were brought.

The positive evidence thus obtained that a 
healthy man could be infected with malarial fever by infected mosquitoes brought from a distance was confirmed, and rendered still more positive by some further experiments carried out by Sir Patrick Manson. Dr. Bignami's experiment was always open to the objection that as the healthy man who volunteered was living in Italy, he might have contracted the fever in some other way than by the mosquitoes which bit him. This objection was removed by Sir Patrick Manson's experiment. He had some infected Anopheles brought from Italy to England. His son, Dr. Thurburn Manson, and Mr. R. Warren, of the London Tropical School, volunteered to subject themselves to the bite of the Anopheles. Neither had ever been in a malarial country, nor resided near a malarial district. It is obvious that if the experiment were successful the evidence was complete. The experiment was carried out and proved successful. Both Dr. Manson and Mr. R. Warren were attacked with malarial fever eighteen days after they were bitten, and the parasites were found in their blood.

It is important for measures of prevention 
to know what kind of mosquito this Anopheles is, and to be able to recognize it in its different Description of the stages of the winged insect, Anopheles and its the egg, the larva and the life-history.

pupa. No other species of mosquito, of which there are many, are malariabearing, so for malaria, at all events, they need not be considered. The great thing is to be able to recognize the Anopheles. In considering the four stages of existence of the mosquito it is necessary to remember that the winged insect spends its life in the air, the egg floats on the water, and the larva and pupa pass their life in the water.

The Anopheles (fig. 5) is a winged insect, from the front of whose head projects a central

\section{Winged stage.} straight proboscis of a stilettoshape. On each side of the proboscis and almost in contact with it are the palpi, of about the same length; on each side of the palpi are the antennæ, or feelers. The body is slender, the legs are long and slender, and the wings are small and may have four spots on their front margin. It is recognized by the position it assumes when it rests, and by being 
noiseless on the wing; it never hums. It rests on the wall on its long legs, with its body sticking out behind at an angle to the wall of $45^{\circ}$ or $50^{\circ}$. Its proboscis almost touches the

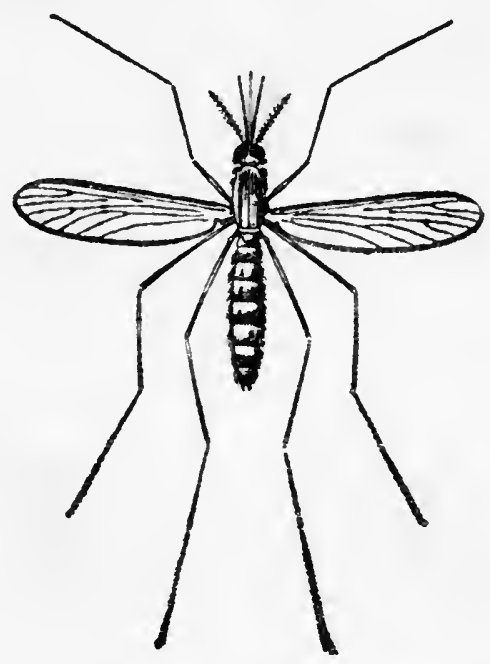

FIG. 5.-Anopheline mosquito (Manson).

wall, and is in the same axis as its body. Proboscis and body are in the same straight line, and form an angle with the wall to such an extent sometimes as to make them almost vertical to the surface. This is a characteristic 


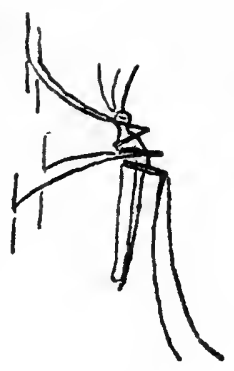

Culex.

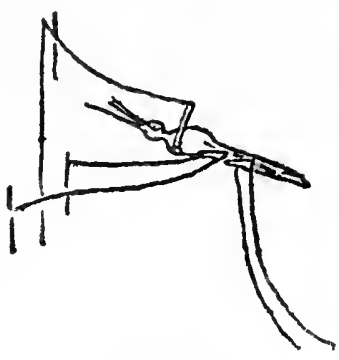

Anopheles.

FIG. 6.-Mosquitoes resting on a wall (Ross).
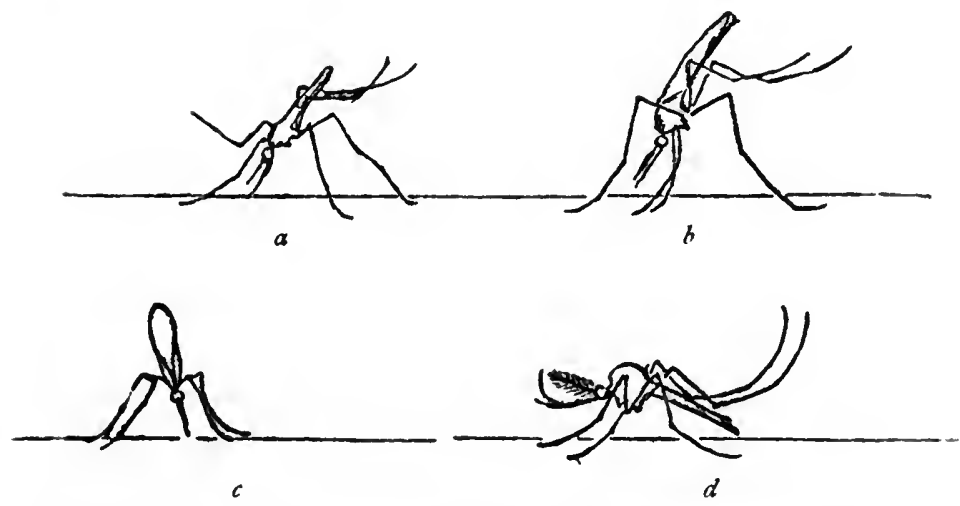

Fig. 7.-a, $b, c$, Anopheles, and $d$, Culex, mosquitoes resting on a horizontal surface (Giles). 
attitude, and differs from other kinds of mosquitoes which, when resting on the wall, have their proboscis curved and at an angle to the body, and not in the same axis, so that they have a curved or hump-backed appearance, unless lying flat against the wall. The contrast in attitude is shown in fig. 6 and fig. 7. Fig. 6 shows the mosquitoes resting on a wall. Fig. 7 shows them resting on a horizontal surface. The difference is very striking. The Anopheles never lies parallel with or flat against the wall. It is always at an angle, with its body sticking well out from the wall.

The eggs of the Anopheles, unlike those of other mosquitoes, require a lens to be distinctly seen. They are then

Eigg stage.

seen to be boat-shaped, and are single, or arranged in small groups, and generally attach themselves to floating objects in the water.

The larvæ of the Anopheles (fig. 8) have a small head, and long, segmented, tapering body. The head is narrower Larval stage. than the first segment of the 
60
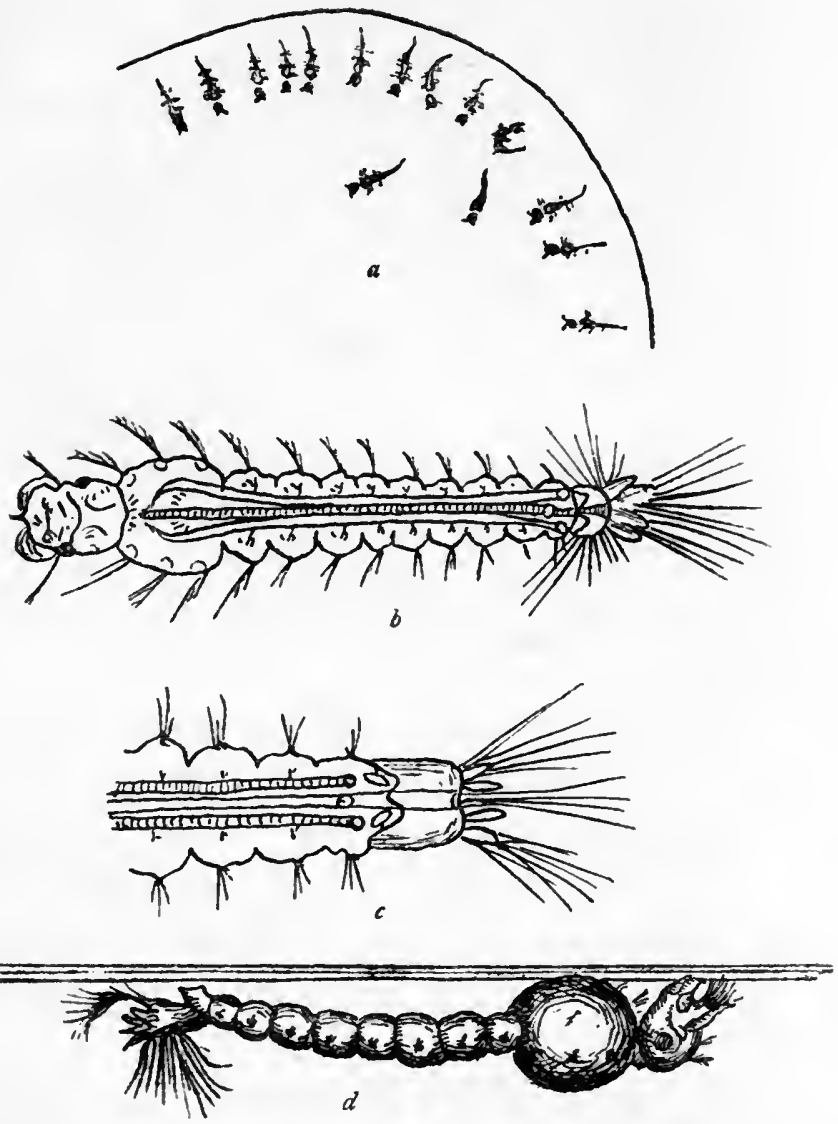

Fic. 8.-Larvæ of Anopheles, a, natural size, floating at surface of water; $b$ (magnified) showing breathing tubes; $c$, section (magnified) showing openings of breathing tubes near tail (Christy). $d$, position at surface of water (Giles). 
body, which is called the thorax. Down the centre of the body run two breathing tubes, which end in two openings in the front part of the last segment. It is because of the position of the breathing tubes that the larvæ
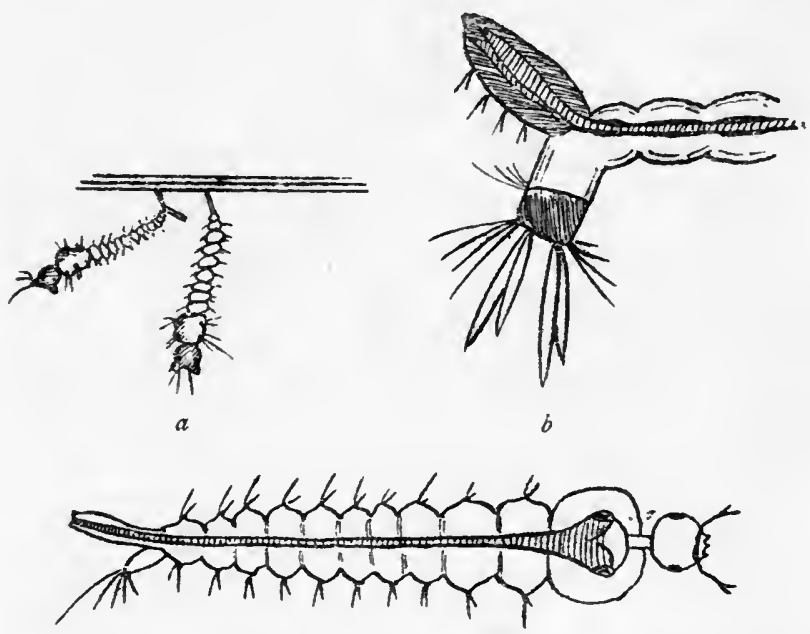

FIG. 9.-Larvæ of Culex. $a$, enlarged, showing position of rest at surface of water; $b$, section showing opening of breathing tubes near tail; $c$, showing breathing tubes (Christy).

of Anopheles usually float horizontally at the surface of the water, differing in this respect from the larvæ of other mosquitoes, Culex which have their breathing tubes ending in a 
long process or flap near the end of the tail, and rest with their heads down in the water, and this flap near the tail only at the surface. Mosquitoes, the larvæ of which hang down in this way, are not malaria breeding. They are the most numerous mosquitoes in the summer. Figs. 8 and 9 give the position which these larvæ assume in the water and also show the position and termination of their breathing tubes, which explain their attitude in the water. When Anopheles larvæ are disturbed, they usually skim along the surface of the water, and seldom go to the bottom. When the larvæ of Culex are disturbed they quickly go to the bottom.

In the course of one to three weeks the larva develops into the pupa. The pupa is shaped like a comma or a sea-horse

Pupal stage.

with a swollen head. It has a paddle-like tail by which, with a series of jerks of its abdomen, it swims rapidly. It has two trumpet-like tubes proceeding like horns from the sides of the thorax. These are the air tubes. In a state of rest the pupa remains immediately under the water, with 
these two air tubes touching the surface. The pupa thus breathes through these tubes near the head instead of through the tail, as the larva does. In two or three days the thoracic part of the pupa splits, and there emerges from it the winged insect, which remains on the sur-
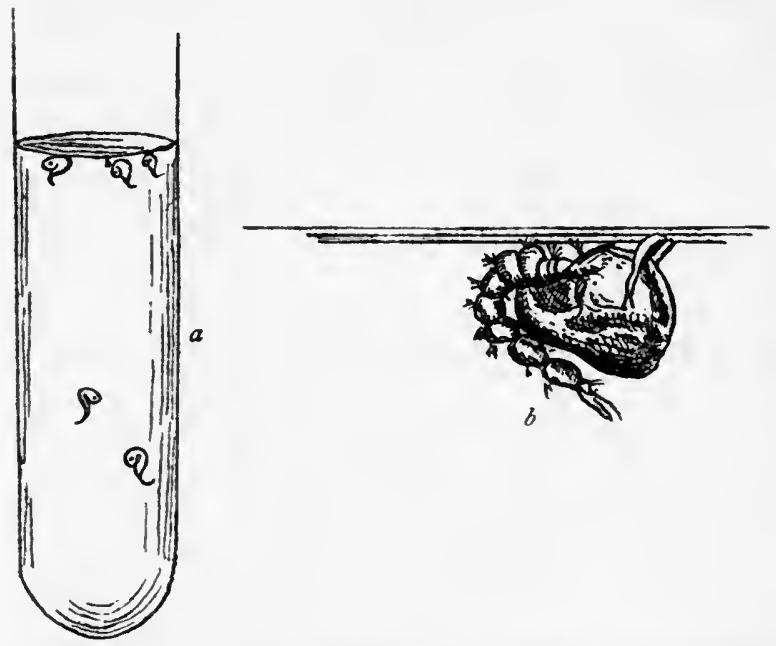

FIG. 10.-The nymphæ or pupæ of Anopheles. a, natural size (Christy) ; b, magnified (Giles).

face of the water, resting on the remains of the pupa until it is enabled to unfold its wings and fly away. Male and female thus take wing, and in this aerial stage the female becomes 
fertilized, and lays her eggs, generally in the same waters from which she emerged.

In the meantime, during the life of the mosquito as a winged insect, the female feeds, if Mode of infection she can, on the blood of man of the mosquito. or beast, and if that blood belongs to a malarial patient with the mature forms of parasites in the red blood corpuscles, the mosquito which was healthy before becomes an infected mosquito, and in eight or ten days, when the development of the parasites within is complete, she will infect any healthy person whom she bites. It is only the female that bites, and it is only the female that can convey malarial infection, for it is in the female alone that the parasites undergo the wonderful development already described. She is for the most part a nocturnal creature, and seldom feeds at any other time than between sunset and sunrise. She inhabits by preference human dwelling places, and is found chiefly in bed-rooms in dark corners and in latrines. The female Anopheles is not always the carrier of the malarial germ, for unless the Anopheles feeds on infected blood it cannot become. 
infected and cannot give malaria. As a newborn Anopheles it is harmless until it has fed on a malarial patient.

The conveyance of malaria from a malarial patient to a healthy person by an infected mosMode of infection quito places malaria in the of human beings rank of an infectious disease. by the mosquito.

In a malarious district the Anopheles has plenty of opportunities of becoming infected. Large numbers of the children, especially under 2 years of age, have parasites in their blood. This is especially the case among natives. It is because of this fact that Europeans living near native huts incur the risk of being infected with malaria. The Anopheles finds in the unprotected native children a happy hunting ground for nourishment. Those Anopheles which feed on malarious children become infected, and then, entering the European houses in search of fresh food, infect by their bites the European inmates, as well as the native servants. The native children get infected by the Anopheles that have fed on the blood of their fathers, mothers, sisters, brothers, other children, or 
visitors coming from an infected locality, who have been suffering from malaria due to a first infection or to relapse of their fever from a former infection, and which has been brought about by chills or other causes.

Such is the history of malaria. It is not absolutely certain whether it is the whole Prexentixe history, or whether the mosmeasures. quito may became infected with the malarial parasite from certain animals and then convey it to man, but sufficient is now known to state that the Anopheles, and the Anopheles only, is the carrier and the disseminator of malaria. It is therefore on this knowledge that all preventive measures against malaria have to be based. Who would ever have thought a few years ago that malarial fever was infectious? Now it has been proved to be so. A patient suffering from malaria is a source of infection to all in close association with him, and even to his neighbours, if there are any Anopheles mosquitoes in the house or which have access to the house and patient.

With the knowledge that infected mosquitoes are the bearers of malaria, and that the 
Explanation of life of the mosquito is so knoxm facts con- intimately associated with malaria. water, in which its eggs,

larval and pupal stage is spent, a flood of light was thrown on our previous experience of malaria. The effect of drainage and sanitary measures, which had abolished malaria under certain conditions, is now explained by the removal of stagnant water which bred mosquitoes. It explained the prevalence of malaria on marsh land. It also explained the fact that malaria might be prevalent in localities where there were no marshes, but where, owing to pools and puddles, water tanks, streams, and insanitary conditions, there was water for the mosquitoes to breed in. The habits of the Anopheles mosquitoes being nocturnal explained why localities that were malarious could be visited during the day with impunity and yet were dangerous at night, and that those who used mosquito nets for sleeping under generally escaped being attacked with malaria. It destroyed the theory that malaria was caused by microbes from marshes, or from the ground, or from bad air. 
Unless a patient suffering from malaria is protected from the bites of mosquitoes until Protection of a he is well, the Anopheles will malarial patient suck his blood and swallow mosquitoes. with it the parasites that it contains, and in eight or ten days inject some of them into the first person she bites. Accordingly, it it necessary in the first place to protect a patient suffering from malaria by a mosquito net. This protects the patient from being reinfected by other infected Anopheles, and it prevents any healthy Anopheles being infected by him. The mosquito net should have a very fine mesh, at least 20 to the inch, because the Anopheles are small and very active, and soon get through ordinary netting. It ought also to be hung from the inside of the frame which is supporting it so that the poles may not interfere with its proper adjustment. The mosquito net must not fall on to the floor, as mosquitoes may then hide under the bed, but should be tucked under the mattress.

The mosquito curtain, however, may not always be effective, owing to the arms during 
PREVENTION OF MALARIAL FEVER

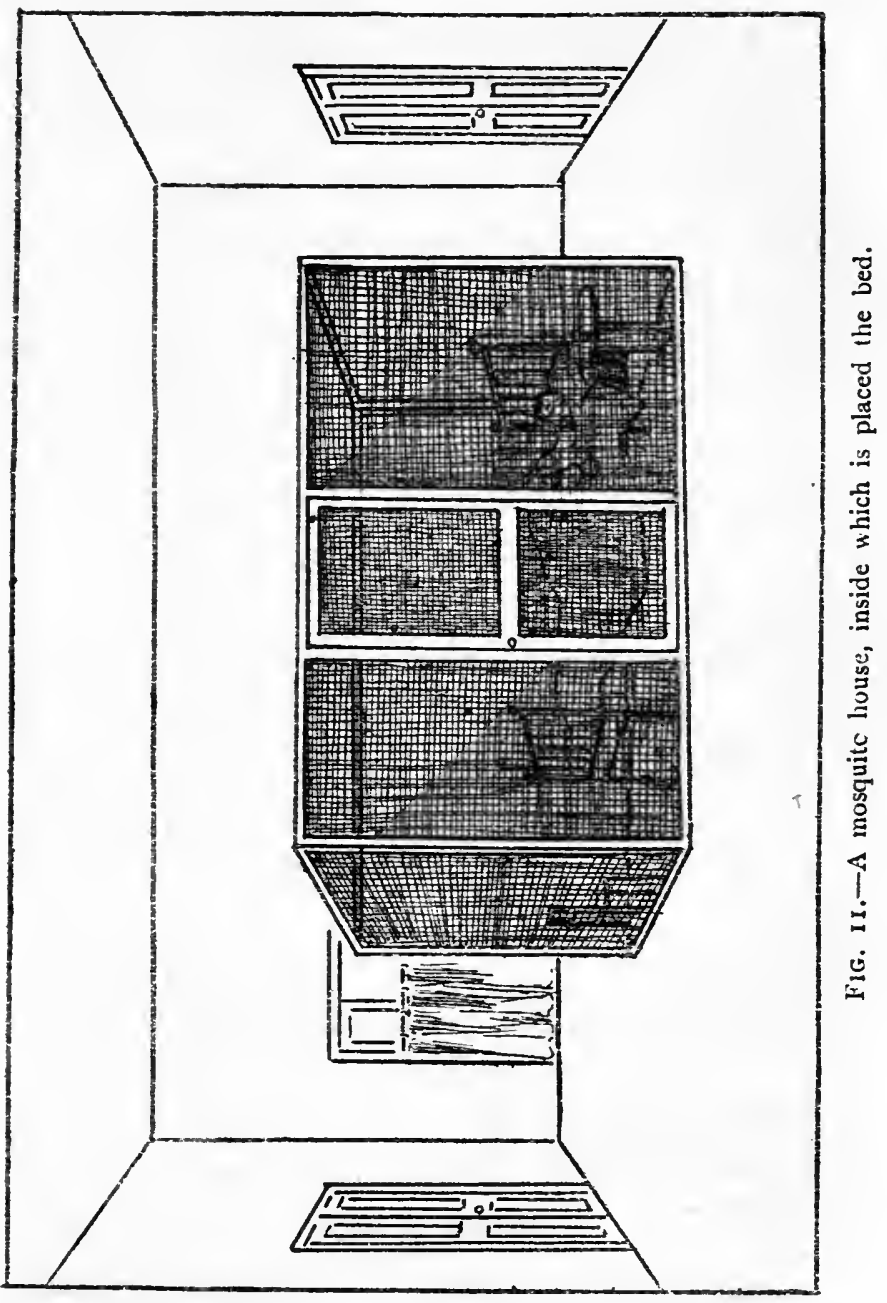


sleep perhaps coming in contact with the curtain. To avoid this, the lower part of the mosquito net for a foot or more should be of double calico. A better and more convenient mosquito-net protection, whether for a sick person or those who are well, is a mosquito house, occupying the best part of the room, and inside of which is placed the bed. It consists of a slender frame of wood and mosquito netting of a mesh of twenty strands to the inch tightly stretched across the frame at the sides and top, or better still, because more substantial, a netting of wire gauze of phosphorbronze with a similar fineness of mesh. It has a door with a spring? to secure its always being kept shut. It resembles a large square tent. Fig. I I represents such a mosquito house.

The proof that people can live in malarious districts without contracting malaria was first demonstrated in the malarious The protection
of healthy people districts of Italy. There, in against bites of its most malarious parts, Pro-
mosquitoes.

fessors Celli and Grassi had certain railway labourers' cottages and peasants' 
reed huts protected from the invasion of mosquitoes. This was done by fixing on the

Italian

experiments. windows and other openings wire gauze netting, and by placing at the door or entrance a wire netting cage or corridor with double doors (figs. I 2 and i3). The mosquitoes already inside the house were destroyed by fumigating the rooms with burning sulphur or other fumigating substance. Quinine was also given to those persons who showed signs of a relapse from a previous attack. The results of these experiments were highly successful. Only a few out of several hundreds living in the protected houses and huts were attacked with malaria, which was in striking contrast to the inmates of neighbouring unprotected houses, who were nearly all attacked. The few who were attacked appear not to have conformed strictly to the rules, which consisted in always being indoors between sunset and sunrise, and if obliged to go out at night, to wear thick gloves and veils. The object of keeping within the protected house or hut between sunrise and sunset is to avoid being bitten by the Anopheles, which feed between these hours. 


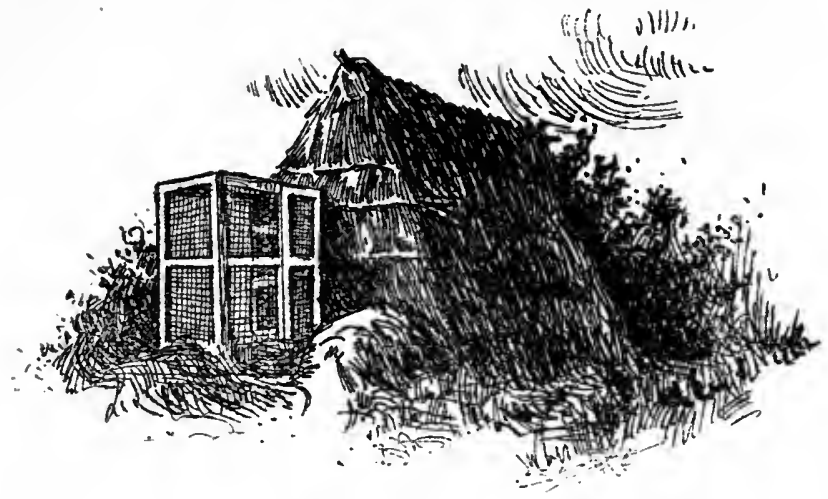

F!G. 12.-Mosquito-protecied hut (Celli).

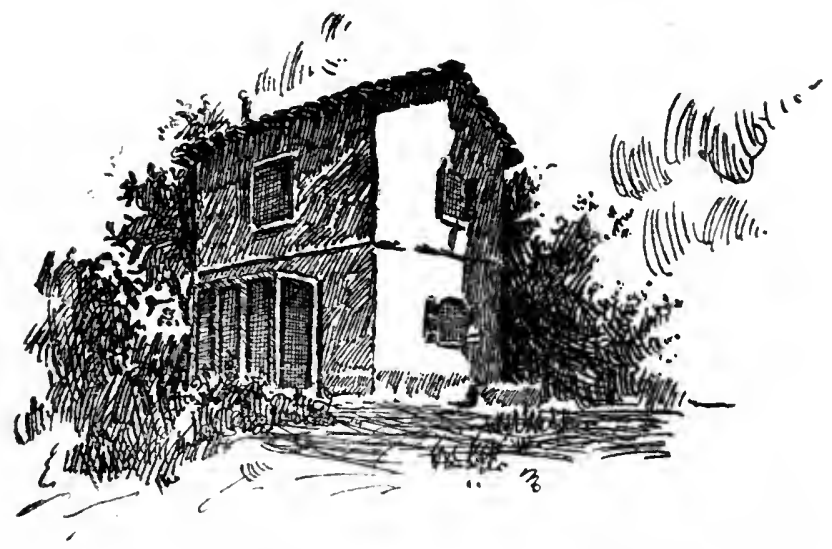

FIG. 13.-Mosquito.protected ouse (C.elli). 
The most rigidly scientific experiment was that carried out by Drs. George Low and Sambon,

British

experiments. of the London Tropical School, who were sent out to the Roman Campagna by Sir Patrick Manson, on behalf of the Colonial Office and the London School of Tropical Medicine. Assisted by the

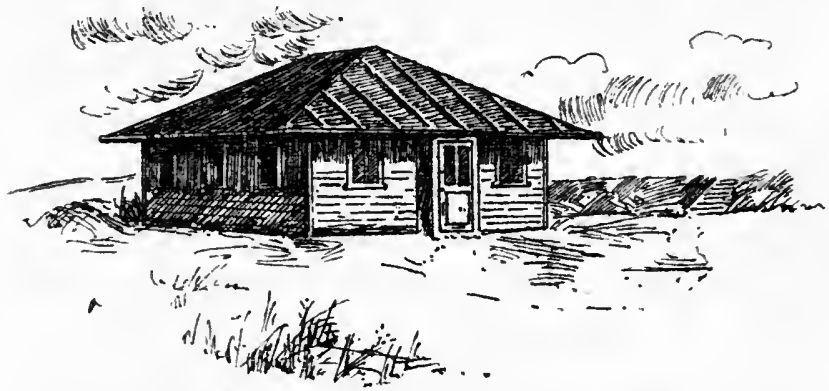

FIG. 14.-Mosquito-protected hut in Roman Campagna for British mission.

Italian authorities, they erected near the mouth of the Tiber a hut whose windows and doors were covered with wire gauze (fig. 14). In this hut Drs. Low and Sambon, with two others, lived for three months during the malarious season, and the only rule they conformed to and the only precaution taken was to be within 
doors before sunset. They spent the day in scientific excursions in the neighbourhood. All four persons in the hut remained absolutely free of fever. While the experiment was being carried out sixteen police came down to Ostia to arrest some anarchists. They spent but one night in the malarious district, but this was sufficient exposure, for every one of them was attacked with fever a fortnight later.

Since these experiments great advances have been made, and the policy of protecting the houses by mosquito wire netting, and fumigating the houses, is extending rapidly and successfully in the malarial districts of Italy.

It is accordingly by the protection of houses from mosquitoes in a highly malarious locality that one of the most important Protection means of protecting healthy of the house. persons from mosquito bites is attained. This protection of houses already built consists in carrying out two measures. The first is to place copper, brass wire or

(a) Mosquito wire screens. phosphor - bronze mosquito netting, of a mesh of at least 20 strands to the square inch, on the windows 
and doors of the house, and the second is to fumigate the house to destroy the mosquitoes. The kind of protection by wire netting is already indicated in the illustrations of the experiments described. The entrance to the house should be by wire-protected double selfclosing doors, so that the chances of any mosquitoes gaining access to the house when the door is opened may be lessened. These doors should be self-closing.

Where it is the custom to sit out in the verandah of an evening it is necessary to protect it by wire netting.

The Anopheles is a domestic creature, and takes up its abode mostly within the house or hut where it can most easily obtain its food. The protection of the house from mosquitoes includes the cellars, if any, or the lower basement, which is often used for stores. These must not be forgotten, for, being generally dark and devoid of ventilation, they are often the hiding places of the mosquitoes during the day. Mosquitoes love darkness and moisture. The bathroom should also be protected.

Besides protecting the doors and windows of 
the house by wire netting, the mosquitoes inside

(b) Fumigation.

the house should be destroyed.

This may be done by fumigating the house with sulphur, the flowers of various species of pyrethrum and chrysanthemum, or by tobacco smoke or wood smoke. Tobacco

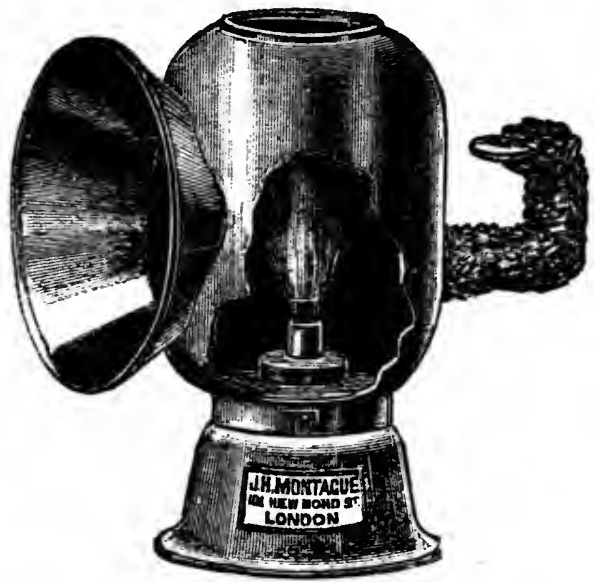

FIG. 15.

smoke has been found to be the most fatal to mosquitoes, but it requires a larger amount than could be generated by large numbers of people smoking in a small room. The burning of the powder of the Dalmatian chrysanthemum or pyrethrum is much more practicable, if veget. 
able insecticide powders are to be used, and if not, then it is better to fall back on the burning of sulphur. The latter, however, has disadvantages in the irritating gases which it generates. Sulphur burnt in an iron pot placed in a tub or basin of water to prevent the burning sulphur falling on the floor can be used, or pyrethrum powder, which has been damped, formed into a cone or pastille and then lighted; or powdered cinerari, one tablespoonful of which should be mixed with nitre and burnt; or if none of these can be had, then burning wood and filling the room with its smoke will all be found to be useful. After fumigation any stray mosquitoes can be destroyed by flapping them with a towel or duster. A chinese lantern similar to that in fig. I 5 is useful for destroying mosquitoes. The funnel-shaped opening, when placed over the mosquito resting on the mosquito netting or wall, imprisons the mosquito, which, in endeavouring to escape, gets cremated by the flame inside.

In building a house in a malarious district a site should be selected well away from native huts. It has already been stated that a large 
(c) Living in a house well axay from native huts and houses.

percentage of native children have malarial parasites in their blood and that native huts abound with infected mosquitoes. It is important, therefore, that the house should be removed from this source of infection besides being protected in the other ways mentioned.

With the protection of the house the principal centre of infection is removed. This, however,

Protection of the indixidual outside the house at night. is not sufficient. Social and other functions will take people out of doors after sunset. Protection from bites of mosquitoes in malarious districts must then be obtained as far as possible, if in a carriage by wraps around the feet and ankles, and if walking by wearing boots instead of shoes, and by wearing large veils and gloves. The veils may be such as are worn while motoring. Veils are useless if drawn tightly across the face. It is advisable to wear putties when out camping or shooting in malarious districts; they prevent mosquitoes biting the legs. The same result is obtained by wearing mosquito boots. If 
ladies do not care to wear putties they should wear kid boots with long tops.

These simple means of protection should be supplemented by other methods to rid the

The methods described must be supplemented by destruction of the larvæo and pupæ of mosquitoes. surroundings of the house of mosquitoes. This can be done by destroying the larvæ, which spend their life in water. As the mosquito always lays its eggs on water, and the larval and pupal stages of its life are spent in water, it is evident that all exposed surfaces of water round about the house are the breeding places Breeding places of laryæ and pupæ.

of mosquitoes. It is these, therefore, that require attention; moats, ditches, obstructed and unflushed drains, tanks, ponds, reservoirs, cisterns, barrels, pots, tubs, broken bottles, or other receptacles containing water, especially if this water is stagnant, serve equally well for the larval life of the mosquito. Pools and puddles formed during the rains by excavations or uneven surfaces of the ground are soon full of mosquito larvæ. On the other hand, without water it is impossible for the eggs, the larvæ, 
and the pupæ to undergo development. The surest mode for their destruction is to deprive them of water. The adult mosquito may hibernate or lie dormant for a long period; but this is not generally the case with the eggs. The larva also may remain for a long period in a resting or dormant stage in water which is not suitable by reason of its temperature for development into pupæ; but neither larvæ nor pupæ can live without water. If they do not get water they die. The larvæ are usually found in ponds, small watercourses, and ditches at the margins where the water is still and where weeds abound, and they are not generally found in large bodies of water, such as marshes, lakes, and rivers. Fish are the enemy of the larvæ of mosquitoes, so that water well stocked with fish does not, as a rule, breed mosquitoes. It is the small puddle near the house that is generally the most dangerous breeding place for malaria.

The shortest period of the water life of the mosquito is a little oxer a week.
The shortest period under most favourable conditions for the eggs to pass through the larval and pupal stages is a little over a week. The 
puddles and pools may therefore remain untouched for that time at least without giving rise to the winged mosquito. This fact is

Measures to be taken to destroy the laryæ and pupæe. made use of in preventive measures against the development of mosquitoes.

Preventive measures may be summed up as regular attention to the local conditions surrounding the house. Every week pots and other receptacles containing water, and therefore liable to be the breeding places of mosquitoes, should be emptied and dried; the drying may be done

Emptying of receptacles containing water, and brushing out puddles.

either by wiping with a cloth or exposure to the sun. Pud. dles should be brushed out with a broom. Vessels and reservoirs containing water which can be spared should be emptied; but if the water is too precious for them to be emptied they should immediately after the Use of mosquito screens for periodical cleaning, to which water reserxoirs all should be subjected, be
and cisterns. protected by mosquito wire netting. The openings of all drinking water 6 
tanks should be screened. Other reservoirs or ponds too large to be emptied should be treated by having added to them petroleum or kerosene. It has already been pointed out that the larvæ and pupæ of mosquitoes come to the surface of the water

Spreading a thin film of oil on the surface of the water.

to breathe. If a thin film of petroleum or kerosene is spread over the surface of the water the larvæ and pupæ are unable to obtain the air they require. They get suffocated and drown. The oil can be spread by a rag on a stick. The disadvantage of petroleum is that it soon evaporates. Tar has greater advantages in this respect, and an old tar barrel placed in the reservoir or pond gives a better film for a longer period. The barrel can be taken out and retarred as required-once a fortnight is probably sufficiently often. In the case of a tank of drinking water the film may be formed by eucalyptus oil, which evaporates even more quickly than petroleum. The mosquito netting is, however, the best protection for tanks or reservoirs containing drinking water. 
All excavations around and near the house, and depressions in which water lodges, should

Filling up the

Filling up the be filled up. The grounds
excavations and around the house should be
depressions, and levelled and drained so that
lexelling and depressions, and lexelling and draining uneven surfaces. there are no pools or puddles. The surface drainage of the house should be kept in good order, regularly flushed down and be kept clean. Well-kept lawns around the house are pleasant to the view, and on account of their direct exposure to the sun do not harbour mosquitoes. The short grass is also useful in drying up the soil and preventing small puddles, which are apt to form in bare soil owing to the unevenness of the ground. A grass lawn of Bahama, Indian or French grass is therefore an excellent subsidiary protection to the house. Ditches should be lined with masonry, so that the flow of water in them during the rainy season is constant, and arrangements should be made for flushing them thoroughly once a week. Ditches near houses not absolutely required for efficient drainage should be filled up. Mosquitoes in small streams on high lands 
have been found to be best dealt with by diverting the water into subsoil drains.

By carrying out these measures systematically the breeding places of mosquitoes around the house and near it will be removed. It is by similar measures to these that such excellent results have been obtained in Havana, in Cuba, Ismailia in Egypt, Panama, Malay States, and other localities.

In malarious districts there is generally a season when malaria is particularly rife, and Quinine as a which is called the malarial prophylactic dur- season. It corresponds, as a
ing the malarial season. rule, with the rainy season, more especially at its commencement and at its end. These are the times when the rainwater, which has lodged in hollows in the ground and formed pools and puddles everywhere, lies there undisturbed, and in its stagnancy is favourable to the life of mosquito larvæ. During the heavier rains the pools and puddles are usually too often scoured out or disturbed to form favourable breeding places.

It is often advisable at the commencement 
of the rainy season and again at its termination, when everything is drying up, to take $5 \mathrm{gr}$. of quinine daily as a prophylactic, or I 5 gr. on two successive days every ten days; for instance, on the roth and I Ith of the month, again on the 2oth and 2 Ist, and again on the 3 oth and 3 Ist. Euquinine being tasteless, though slightly more expensive, is far better for routine use as a prophylactic. Persons who have once had malarial fever should use quinine systematically as a prophylactic for at least two years, continuing its use at home. Quinine will greatly assist the protective measures recommended, but it will not provide protection without those measures. Care also must be taken to avoid chills as much as possible, in order to prevent relapses of malarial fever.

The Indian Government has facilitated the purchase of quinine by selling it at cost price at every post office in India ; Sale of quinine at thus the villagers of malarious
exery post office. districts have no difficulty in obtaining quinine. Some of the Colonial 
Governments have done the same. It is a procedure that might be adopted with advantage by other Governments having malarious possessions.

\section{Yellow Fever and Filariasis.}

The discovery of the rôle of the Anopheles in the production of malarial fever has led to the further discovery that other mosquitoes of the Culex variety spread two such formidable diseases as yellow fever and filariasis.

The larvæ of the Culex, it will be remenbered, have their breathing tubes opening in a prolongation from the tail (see fig. 9, p. 6r). It is because of this that when they come to the surface of the water they remain suspended from the surface by their tails, their heads hanging down in the water. It is by this attitude that they can be easily recognized in contradistinction to the Anopheles, which lie horizontally with the surface of the water (see fig. 8, p. 60).

Yellow fever has its principal home in the ports on the Gulf of Mexico and the islands close by. From there it has

Yellow fexer. spread to many of the ad- 
jacent ports in Southern America and has found a secondary home. At times it has visited the islands of the West Indies, manifesting itself in severe epidemics. In the days of Columbus it reached Cape Verd Islands, later the Gulf of Benin, the Canaries, Senegal and the Gambia, and has been known to be endemic on the West Coast of Africa since the middle of the eighteenth century. Cuba until recently was one of its chief endemic centres. Early in 1901, Read and certain other American physicians proved by their researches that yellow fever was spread by the bite of the mosquito known as the Stegomyia. This mode of infection had been suspected as far back as 1853 , when Dr. Louis Beauperthuy first pointed out that marshes were not unhealthy in consequence of the putrescence of the water but owing to the presence of mosquitoes, and that the mosquito with legs striped with white was the agent of infection for yellow fever. Dr. Charles Finlay, in I 880, reiterated this view and supported it by some experiments. Read and his associates, however, established beyond doubt that the Stegomyia calopus or fasciata 
was the conveyor of the yellow fever infection. Being a practical people, the Americans soon put into practice the information derived from this discovery. General Wood, the Governor of Cuba, who was himself a medical man, took immediate steps, with his sanitary officer, Dr. Gorgas, to prevent yellow fever in Cuba. Measures were introduced to destroy the larvæ of mosquitoes in the town, to destroy the adult mosquito in the houses, and to screen all the sick from mosquito bites. The result was remarkable. There was an immediate drop in the yellow fever mortality. For the ten years previous to I90 I the average mortality was 467. For the year after the operations against the mosquito were begun the mortality from yellow fever was only five. The preventive measures have been regularly continued and used, and now, for the first time in 150 years, Cuba is free of yellow fever and continues to be free.

An additional interest attaches to this very successful campaign against yellow fever, and it is that the clearing of the town of Havana of mosquitoes generally has also resulted in 
a remarkable reduction of the mortality from malarial fever.

Everyone knows the success attending the construction of the Panama Canal by the Americans. The genius of De Lesseps was foiled by malaria, yellow fever and dysentery. The failure was not due to any lack of ability to overcome engineering difficulties, but to the terrible mortality among the men engaged on the work. It is estimated that some 50,000 men perished in that ill-fated enterprise. The Americans decided to combat these diseases, to exterminate the mosquitoes and to carry out large sanitary operations, with the result that the Panama Zone has been changed from a pestilential locality into one even more healthy than. some of the most healthy places in the United States.

It may be mentioned here that it is only during the first three days of the illness from yellow fever that the patient can infect the mosquito, and that the infected insect cannot communicate the disease until after the lapse of twelve days. Every person attacked with yellow fever should be screened in bed under 
a mosquito net to prevent any Stegomyia biting the patient and becoming infected.

The Stegomyia fasciata, or tiger mosquito, which is the carrier and transmitter of yellow The Stegomyia fever, is to be found on the fasciata. sea coast of tropical and subtropical countries. From the seaports it may spread inland by rail and by river, sometimes establishing itself in the interior far from the coast. It is carried from port to port by ships, boats and canoes as the winged insect in some hiding place, or as mature larvæ hatched from the eggs laid in some receptacle of water by Stegomyia. The Stegomyia fasciata is domestic in its habits, and is generally present where rainwater is collected and stored for drinking. It is easily identified by its dark colour, the white bands on its legs and abdomen, and by the white lyre-shaped marking on the back of the thorax (fig. I6). The female only bites and sucks blood, and this she may do not only at night like the Anopheles, but also during the day. The eggs are laid on the surface of the water, often on floating or moist leaves, and are minute, dark and cigar-shaped. They 
hatch out very quickly, a day or two sufficing when the weather is favourable. The larvæ, owing to the position of their breath-

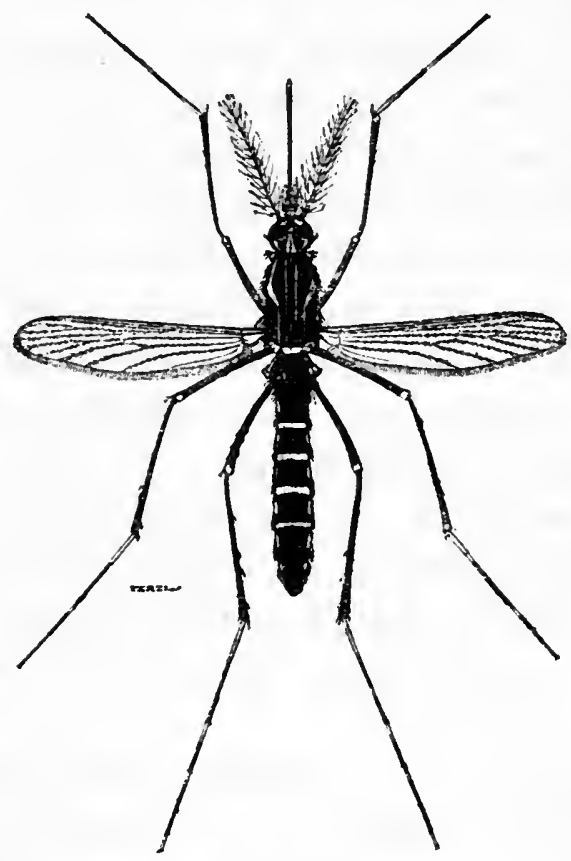

FIG. 16. - The tiger mosquito (Stegomyia fasciata). Six times natural size.

ing apparatus, are suspended by their tails from the surface of the water with their heads down. The slightest disturbance causes them 
to wriggle downwards out of sight to the bottom of the water receptacle. From this motion and their activity they are called "wrigglers" or "wiggle-tails" or "wigglewaggles." Barrels or other receptacles containing water, unless protected, are apt to be full of them, and form a constant breeding place for Stegomyia which, as the winged insect, invades the house and torments the inmates. The presence of Stegomyia in a house is a sure sign of stagnant water on the premises. When disturbed the larvæ quickly retreat to the bottom of the barrel or receptacle they are in and if there are cracks or crevices many may hide in these. Care should therefore be taken when emptying such that these hiding places are thoroughly washed out and the larvæ removed.

To prevent the breeding of Stegomyia all barrels and receptacles of water should be Prevention of emptied once a week and breeding of Stegomyia. thoroughly dried. The larvæ, being deprived of water in which they live, consequently die. If the barrels are used for storing drinking water, and 
cannot therefore be emptied, they should be screened by a wire netting cover. Similarly, water cisterns should be screened and a little eucalyptus oil or kerosene poured on the surface. As the water is drawn from the tap near the bottom of the cistern there is no risk of the oil which is floating on the surface mixing with the water and rendering it unpalatable; no stagnant water should be allowed on the premises. Kerosene or petrol should be poured once a week into any cesspool that may exist in or near the premises.

Filariasis is the term applied to the presence of a worm-like parasite, known as filaria, in the blood of persons who have

Filariasis. become infected. The filariæ live in the blood, sometimes causing no inconvenience, but in other cases they are the cause of serious diseases, one of which is elephantiasis.

It is now many years ago since Sir Patrick Manson, working in China, made the discovery that the filaria is extracted from the blood of a filarial patient by the mosquito, and that in the body of the mosquito the parasite 
undergoes another cycle of life. It remained for Dr. Low, of the London Tropical School, one of Sir Patrick Manson's pupils, to demonstrate that the young embryos get into the proboscis of the mosquito, and in this way, when the mosquito bites, the embryos are injected into a healthy person, thus infecting him. The mosquito infected with filaria spreads filariasis in a similar way to that in which the mosquito infected with the malarial parasite spreads malaria.

It will be clear, therefore, that the protection from mosquito bites has an all-important Measures against bearing on the prevention of mosquitoes will malaria, yellow fever, and filayellow fever, and riasis. In any district in which flariasis.

any of these diseases prevail it is only courting an attack if mosquito nets are not used for the bedroom and mosquito wire protection for the house, in addition to the regular destruction of larvæ in the immeIndividual diate vicinity of the house. effort necessary. 'This is the duty of the individual to himself. Further measures, however, require to be taken by the local authority. An 
Measures by the local authority also necessaxy.

individual may take the necessary precaution so far as lies in his power to protect himself, but a careless neighbour may materially assist in neutralizing the beneficial effects of the precautions by having large breeding places for mosquitoes next door. It is here that the co-ordinating powers of the local authority is required. The local authority should insist that certain precautions should be taken by each householder to prevent breeding grounds of mosquitoes being formed or retained, and should enforce by prosecutions and fines any breaches of the regulations or laws in this respect. Their inspectors should regularly inspect not only the premises of and surroundings of the poorer class, but also those of the richer, where puddles are very likely to be found. The local authority should maintain a mosquito brigade, such as advocated by Sir Ronald Ross, to drain marshy ground, maintain good drainage, remove puddles, rubbish, broken crockery, bottles, opened tins, and rank vegetation, and it should employ an efficient sanitary service. 


\section{Relapsing Fever and Insects.}

The name of relapsing fever indicates the nature of the illness, which is characterized by a series of alternating periods of high fever, continuing two to eight days, and periods of freedom from fever lasting several days. The accessions and subsidences of fever may go on for several weeks or longer. The malady, except in the feeble, starved, and aged, has only a small mortality.

The symptoms are not dissimilar to those of malaria. There may be a few days of

Symptoms. malaise and then there is a sudden attack of high fever, intense headache, pain in the left side over the spleen, vomiting, rapid pulse, slight yellowness of the eyes, and sometimes jaundice. There may also be a diarrhœal or dysenteric attack. The fever continues for about a week, when there is a profuse sweat and the temperature rapidly falls, sometimes below the normal. The patient feels better. This improved condition lasts for several days, and then there is a relapse and a recurrence of the same symptoms as before, and so the cycles go on and 
repeat themselves, perhaps many times, before permanent recovery. Natives suffer from the disease, but generally in a milder form than Europeans. This is thought to be probably due to an attack during childhood, affording a certain degree of immunity.

The blood of a patient with relapsing fever contains minute microbes made up of fine Spirochæetes the filaments or threads of a wavy causal agent in or spiral form. These are the the blood. spirochætes, which are the cause of the disease in all its varieties, of which there are several, such as the African, Persian, Indian, European, and American.

The African variety of relapsing fever is often called tick fever, as it has been proved to be due to the bite of a tick

Modes of

Transmission. infected either by sucking the blood of a patient suffering from the disease or by being the direct descendant of a tick that has thus become infected. The ticks which transmit the disease in Africa are the Ornithodorus moubata (fig. 17), and Ornithodorus savignyi, while in Persia it is the Argas persicus, or fowl tick (fig. 18). 
98

They lay their eggs in the ground or in crannies in the wall, and under favourable conditions the young hatch out in about three weeks.
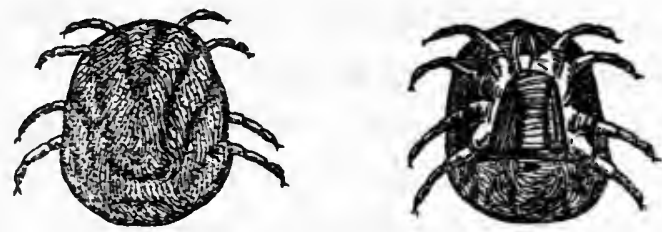

F1G. 17.-Ornithodorws moubata.

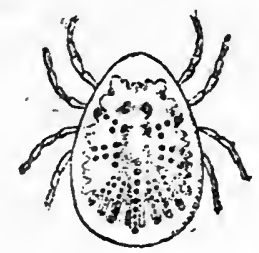

F1G. 18.-Argas persicus.

The ticks once infected remain probably infective for their lifetime. The several varieties of relapsing fever which occur in other parts of the world than in Africa are believed to be transmitted by the bite of the body-louse, Pediculus vestimenti (fig. 20, p. 105); suspicion also attaches to the bed-bug, Cimex lectularius, (fig. 19) The spirochætes are drawn from 
the blood of a patient by the tick, body-louse, or bed-bug, according to the country in which the disease prevails or the opportunity afforded for the insect. Once in the stomach of the insect the spirochætes multiply in numbers, and when the insect bites a healthy

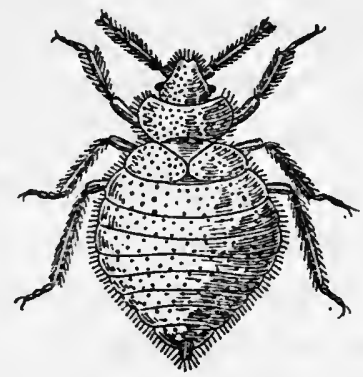

FIG. 19. - Cimex lectularius (Castellani and Chalmers).

person it extrudes a quantity of the microbes near the wound, which, when scratched, becomes infected with them. The spirochætes then find their way into the blood of the person bitten, and after a varying period of from two days to a fortnight set up the disease.

The tick is usually associated with the domestic life of man, with his beasts of burden, to which the tick attaches itself and is brought 
Habits of the tick to his home, and with the fowls, and precautions to be taken

against it. that in backward countries have a closer association with the dwelling than in those more advanced. It lives in infected districts in the cracks and crannies of the walls and mud floors of wattle and daub huts and in the thatch of the roof, and comes out at night. It is also to be found in the insanitary surroundings and refuse heaps of huts and camps, on the bundles of native travellers and porters, in the soil and surround. ings and undergrowth of old camping grounds occupied by these, and in rest-houses of caravan routes and highways of travel, also on horses and under the shade of trees and around the wells and localities where animals are watered.

In travelling in infected districts it is safer to encamp some 50 yards away from native huts and an equal distance from wells, the soil and surroundings of which may have become infected by travellers and their animals. It is also necessary to avoid old encampments. If a native hut has to be used, then the camp bed should be placed well away from the walls, 
the mosquito curtain carefully adjusted, and a lamp kept burning during the night.

The traveller should never sleep on the floor of a native hut.

Bites should be painted with tincture of iodine.

The precautions recommended to be taken by officers in the East African and Uganda Services when travelling in tick fever districts are as follow :-

(I) In a wattle and daub house always sleep well away from (the fissures in) the wall and have the bedding raised off the ground.

(2) When blankets and bedding are being hung out to be aired, see that they do not sweep the ground.

(3) Avoid old camping grounds as far as possible, and do not allow the porters to occupy old huts or disused shelters or utilize old grass, either for beds or thatching.

(4) An easily made poison for insect pests for use on a mud floor is a strong decoction of native tobacco regularly applied. It is more important, however, to fill in all cracks as they occur and to apply a coating of 
cow-dung at regular intervals. The cow-dung should be mixed with a solution of the strength of $I$ in 500 corrosive sublimate.

(5) It is advisable to have bedding packed in a tin box so that ticks cannot adhere to it, as native porters often carry the tick in their clothing.

Infected huts, if of a temporary character, are best dealt with by burning; all refuse

Destruction of ticks. near the hut should be burnt, and the grass or undergrowth around should also be burnt, and this should be extended to the surroundings of the well. Permanent buildings should be washed or sprayed with crude petroleum, oil of turpentine, kerosene, or hot tar, and then lime-washed. Infested fowl-runs, crates, or dovecots should be burnt. The fowls should be isolated and treated.

Bugs can be exterminated by fumigating with burning sulphur. After sealing up the Destruction room, $2 \mathrm{lb}$. to $3 \mathrm{lb}$. of sulphur of bugs. should be placed in a bowl, which should be suspended or fixed over or placed in a vessel containing water. This is a precaution against fire, due to the possible 
overflow of the burning sulphur. Add a little methylated spirit or alcohol to the sulphur and then set it alight. The room should be closed for twenty-four hours. The fumigation should be repeated at intervals of a week for three successive weeks. The interval is to allow time for the young bugs to hatch from the eggs that have not been affected, so that they can be killed by the next fumigation before they reach maturity and have laid fresh eggs.

Bugs can be destroyed by washing or spraying the infected parts with kerosene and oil, oil of turpentine, crude carbolic acid or crude creosote, or with 5 per cent. crude petroleum oil, or 1 in 500 corrosive sublimate, but the latter is injurious to metals. As the bugs hide in crevices and cracks in the wall, floor and bedstead and behind pictures, match-boarding and wainscoting, and inside wardrobes and cupboards, care has to be taken that in the application of these insecticides the habits and hiding-places of the bug are remembered and provided against.

A very liberal washing of bedsteads with a mixture of boiling water and soap is also useful 
in destroying bugs or their eggs, especially ir followed by smearing with vaseline. Vinegar is also an excellent application to furniture infested with bugs. In some countries natives in towns near the sea regularly rid their bedsteads and mats of bugs and fleas by soaking them in sea-water.

Lice may be contracted when travelling by coming in contact or association with verminous persons, or by sleeping in some unclean inn or bed which has been previously occupied by a verminous person, or by one's bedding and clothes becoming infected by getting mixed up with others that are verminous.

Of lice affecting men there are three kinds - the Pediculus capitis, or head-louse, the The different Pediculus vestimenti, or bodykinds of lice. louse (fig. 20), and the Pediculus pubis, or crab-louse (fig. 21). They may be all carriers of disease, but the body-louse, which lives under the folds and seams of the underclothing, and only comes out from these to feed, differing thus in its habits from the other two, which live hidden in the hair of the body, is considered to be the most important, in that it 


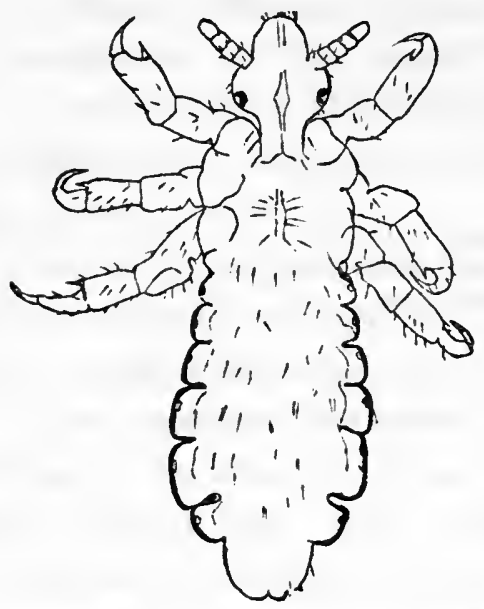

Fig. 20.-Pediculus vestimenti, or body-louse.

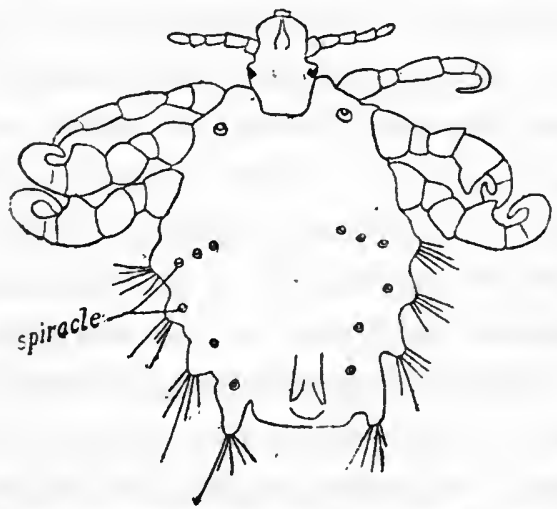

FIG. 2I. Phthirius inguinalis, or crab-louse (Alcock). 
is believed to be an active agent in spreading not only relapsing fever but also typhus fever.

The precautions necessary are to be careful as far as possible to keep bedding and kit

\section{Precautions}

against and de- ling, avoid sleeping in unclean struction of lice. apart from others when travelplaces, carry a small stock of flowers of sulphur, cresol soap, soft soap, oil, vaseline, kerosene, creasote, and a bottle of corrosive sublimate tabiets. If likely to be in an infected place, the bedding and clothes should be sprinkled with flowers of sulphur, and the inside of underclothes, especially the seams, should be rubbed with the sulphur.

In the event of infection with Pediculus vestimenti, or the body-louse, clothes which cannot be injured by heat should be boiled, baked, or steamed, and then ironed, especially over the seams. Articles of clothing liable to be damaged by heat should be soaked in a solution of corrosive sublimate of the strength of $I$ in 500. When dealing with large quantities these can also be exposed to the fumes of bacterol, or burning sulphur in a portable disinfector.

Among remedies for lice, bugs, \&c., creasote is the most powerful and most enduring of all 
insecticides. Ironing of the seams of clothing and the inside surface of folds in the clothing with a hot iron or hot stone is destructive to the lice that hide under them and to the eggs that have been deposited there. Smearing the inside of seams with vaseline, soft soap and oil, or other greasy substance suffocates the young lice as they hatch from the eggs.

Since the outbreak of the great War, soldiers have become much infested with lice, and much attention has been paid to measures of prevention and to remedies. Dr. S. Monckton Copeman, F.R.S., found the following so effective as to have it put in orders :-

After bathing and drying themselves men were to lather their bodies with cresol soap solution, especially over hairy parts, and to allow the lather to dry on. Shirts were to be washed in cresol soap solution made with boiling water. Tunics and trousers were to be turned inside out and rubbed with same lather, especially along the seams. Lather was to be allowed to dry on the latter. Soap Solution.

\begin{tabular}{|c|c|c|c|}
\hline Jeyes' fluid & $\cdots$ & $\cdots$ & \\
\hline Soft soap & $\ldots$ & $\ldots$ & $\ldots$ \\
\hline Water & $\ldots$ & $\ldots$ & $\ldots$ \\
\hline
\end{tabular}


Major Lelean recommends the making of a tubular bag from a 2 in. loose-woven bandage, putting into it two teaspoonfuls of N.I.C. powder, which consists of a mixture of-

$\begin{array}{lllcc}\text { Naphthaline } & \ldots & \ldots & 96 \text { per cent. } \\ \text { Iodoform } & \ldots & \ldots & 2 & " \\ \text { Creosote } & \ldots & \ldots & 2 & " 1\end{array}$

The powder is evenly distributed in the bag, which is then worn round the waist.

For Pediculus capitis, or the head-louse, a mixture of kerosene and oil in equal parts rubbed into the scalp at night and protected by a bandage or muslin cap, and then in the morning washing the head thoroughly with soap and hot water, and afterwards combing the hair with a small tooth comb dipped in vinegar to remove the nits will get rid of headlice. Care must be taken, however, in the use of lights when employing kerosene, for it is inflammable. Oil of sassafras is often used instead of the mixture of kerosene and oil, and has the advantage of not being inflammable. A third simple remedy is using a decoction of quassia instead of the kerosene.

For Pediculus pubis white precipitate oint- 
ment can be applied to the parts affected, which should be washed with soap and water two or three times a day.

Certain powders have been used as insecticides; of these the most effective, according to Professor Castellani, are :

Insecticide powders.
(I) Guaiacol powder, which consists of a mixture of 2 or

3 parts of guaiacol to 100 parts of oxide of zinc; (2) menthol powder in the proportion of 2 or 3 parts of menthol to 100 parts of oxide of zinc. Of the two, the guaiacol powder is the most rapidly destructive to body-lice, fleas and bugs, while menthol is pleasanter and destructive to body-lice and fleas.

The essential oils also, such as anise, eucalyptus, citronella, sassafras, made up in powders with oxide of zinc in the proportion of 2 per cent. of the oil, are useful insecticides.

It may be stated generally that kerosene, petrol, creosote, or oil of turpentine, when applied direct or by means of spraying, is fatal to bed-bugs, lice, ticks, fleas, and wasps. For fumigation purposes the burning of flowers of sulphur is the most useful gaseous insecticide. 
It destroys lice, fleas, bed-bugs, flies and mosquitoes.

\section{Phlebotomous or Sand-fly Fever.}

Sand-fly fever is caused by the bite of the minute yellow-brown sand-fly (fig. 22), which lays its eggs in the damp crumbling masonry of

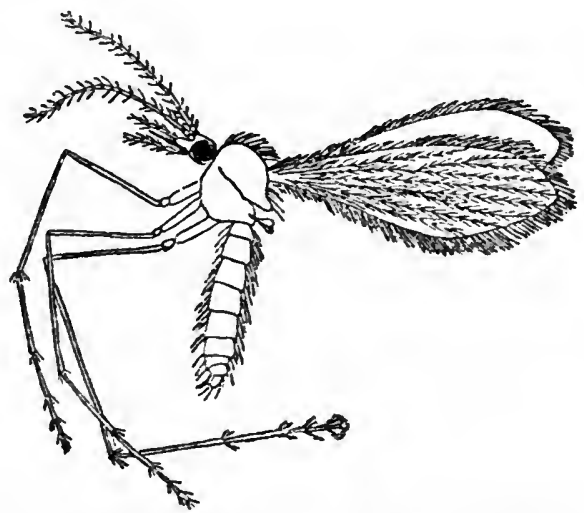

Fig. 22. - Female Phlebotomus, or sand-fly (Alcock).

old cellars and other such dark places. The fever lasts from three to five days, sets in with intense headache and severe pains in the limbs and back accompanied by a rise in temperature to $103^{\circ} \mathrm{F}$., or $104^{\circ} \mathrm{F}$., which ends with sweating and leaves the patient very weak for a few 
days longer. Quinine is of no benefit. Rest in bed, cold applications to the head, and perhaps to $\mathrm{gr}$. of aspirin, is the best treatment to be adopted until medical aid is obtained. No ordinary mosquito netting is protective against sand-flies, but netting with thirty strands to the inch is effective.

Trypanosomiasis or SleEping Sickness.

Sleeping sickness, or negro lethargy as it used to be called, has been known on the West Coast of Africa from a History. very early period, but little attention was paid to the disease until 1903. In that and the following year, in an epidemic in Uganda which destroyed over 200,000 of the inhabitants on the islands of Lake Victoria and its shores, protozoa called trypanosomes were discovered by Dr. Castellani in the cerebrospinal fluid of those affected, and these trypanosomes were proved by Sir David Bruce by a series of experiments and investigations to be the cause of sleeping sickness, and to be spread from patient to patient by the bite of a particular kind of tsetse-fly, the Glossina palpalis. 
Bruce had previously, in I 897 , clearly demonstrated that nagana, in Zululand, a disease which was fatal to horses and cattle, was caused by a trypanosome conveyed to them by the bite of a tsetse-fly, the Glossina morsitans, which had fed on the blood of big game which were acting as reservoirs for this parasite without injury to themselves.

In I901, a year previous to the commencement of the Uganda epidemic, Dr. Dutton discovered trypanosomes in the blood of a European resident in the Gambia, West Africa, who was suffering from fever and enlarged spleen. The disease was called trypanosomiasis, but after the discovery of the trypanosomes in the Uganda epidemic it was found that these two diseases in West Africa and Uganda were the same, that the sleepiness which affected the patient was only the final stage of the fever and enlarged spleen produced by the trypanosomes in the blood and cerebrospinal fluid, and that the Uganda epidemic was probably due to men ill with the disease coming from localities in the Congo where the disease was prevalent, and infecting 
the Glossina palpalis on the shores and islands of Lake Victoria. These infected Glossinze in their turn infected the inhabitants.

The disease may be slow or rapid in its progress. It begins with fever, generally

Symptoms. accompanied with a skin eruptıon, followed by swelling of the glands in the neck. The patient may not look ill at this stage. Later there is a change in the disposition; there is a state of nervousness, tremor of the tongue and parts of the body, and subsequently a state of apathetic dulness or lethargy, sinking finally into the sleeping sickness stage which ends in death.

The Glossina palpalis (fig. 23) is a small dark-coloured fly about $\frac{1}{2}$ in. long. It has

The Glossina palpalis and its habits.

a straight, long proboscis projecting out in front of the head. When resting it closes its wings like a pair of scissors, and when on the wing produces a continuous buzzing noise. It is fond of shade, settling under one's umbrella or helmet, or under the seat when travelling in a train, and awaits its opportunity to bite. Its favourite sites for attack are the 


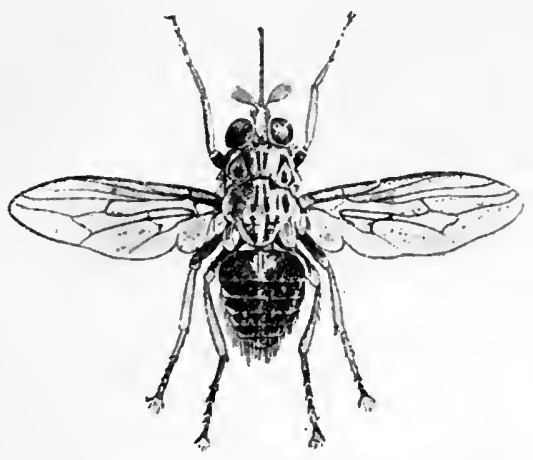

$a$
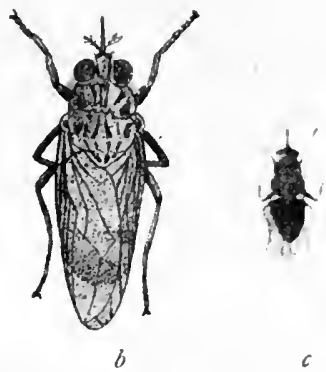

FIG. 23.-Glossina palpalis. a, on the wing (enlarged); $b$, in the resting position (enlarged); $c$, natural size. (Graham.)

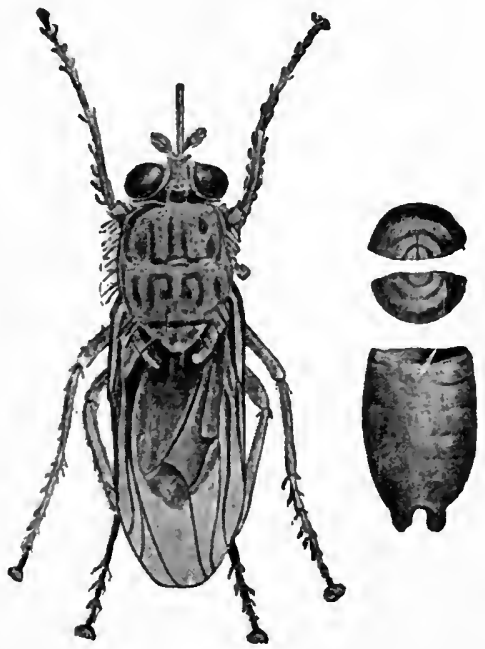

FIG. 24.-Glossina palpalis and puparium. (After Brumpt.) 
back of the neck and back of the knee. It is found in tropical Africa haunting the banks of rivers, streams and watercourses and the shores of lakes, especially where the ground is heavily shaded with undergrowth, high grass

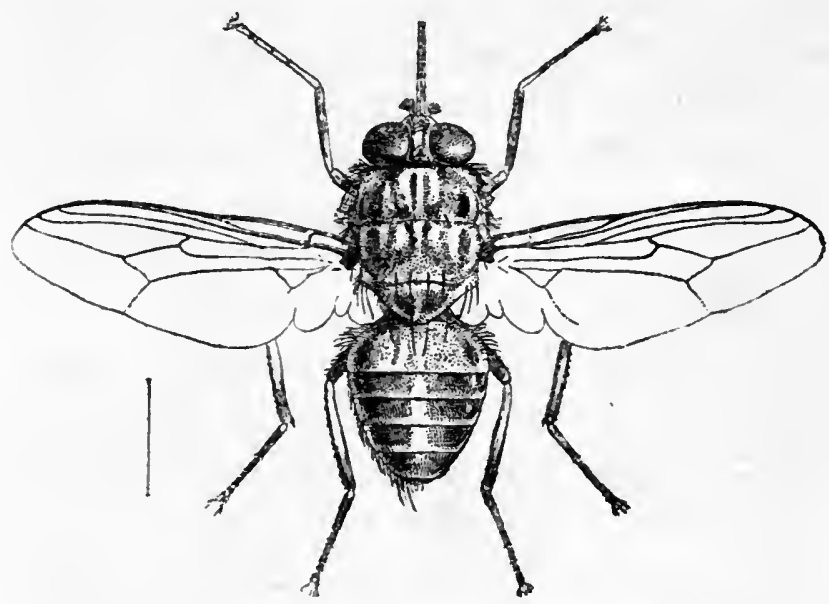

FIG. 25. - Tire tsetse-fly (Glossina morsitans, Westwood).

and herbaceous plants, such as the banana. Papyrus swamps, whether connected with river or lake, are generally free of the fly. The Glossina palpalis may be found in the bush a mile away from the lake or river, and the Glossina morsitans (fig. 25), which is another tsetse-fly that has been discovered lately to be 
also an agent in spreading trypanosomiasis in man, may be found a considerable distance from water, preferring the open country. A third species which has been found naturally infected with the trypanosome is Glossina brevipalpis. This species remains at rest during the day and only bites after sunset or before dawn. The Glossinæ may be carried in boats, canoes and railway carriages, or by native porters, long distances.

But as regards Glossina palpalis, the general rule is that its chief haunts are close to the water's edge, where it was bred, and it bites during the day and not at night. In infected areas, fortunately only a small percentage of the Glossinæ are infected.

The fly does not lay eggs, but gives birth to fully developed larvx, which immediately bury themselves in loose and dry soil around the roots of trees or shrubs, generally within $30 \mathrm{ft}$. of the water of the lake or river; or they may hide themselves under the bark of trees, or in crevices in rock, also in sand, but always close to the water. The larva then become transformed to pupæ in a very short time, 
The pupa (fig. 24) has an ovoid body with twelve segments, and has at its anterior extremity a bifurcated longitudinal seam, which opens to permit the escape of the fly, and on its posterior end two tumid lips.

For those in fly-infested districts, the followPrecautions. ing advice is given by the Colonial Office :-

(I) It is the height of folly to wear shorts; the officer should expose as little as póssible of his bare skin.

(2) Where the fly is numerous, some form of neckerchief should be worn.

(3) Avoid such amusements or occupations as boating, fishing, or shooting close to shaded banks where the fly is known to exist.

(4) Always camp 200 to 300 yards away from infested watersides in as clear a space as can be found.

(5) Do anything that has to be done near or on the water in the fly range either in the early morning or in the late afternoon, when the fly is less active.

(6) In boat travelling keep at least 50 yards from the shore. 
It is a part of the duty of governments to see that houses in $f y$ areas should be renPreventixe dered fly-and mosquito-proof ; measures. that they should not be built near the water, and that the area around them should be cleared of all undergrowth and tall grass ; that ferries, landing-places, public wells and roads leading from them in fly localities should be cleared for some roo yards from the water's edge, and that the traffic between infected and healthy localities of natives and native porters on a large scale, for commercial purposes, should be supervised and medically controlled. If obliged to travel through a flyinfected belt, it is safer to do so during the night. Boats on rivers passing infested. or infected localities should be protected by mosquito wire screening.

The Enteric Fevers, or Typhoid and Paratyphoid Fevers.

The enteric fevers are now known to include not only typhoid fever but also certain paratyphoid fevers, whose symptoms simulate those of typhoid so closely that it is only 
recently, owing to advances in bacteriology, that they have been separated from true typhoid. Next to malaria, typhoid and paratyphoid fevers are the most common infectious diseases among Europeans in Asia, though they are by no means so common in many parts of the tropics.

The paratyphoid fevers are, as a general rule, less severe in their symptoms and effects, shorter in duration and less fatal than typhoid, and since they were at one time included among typhoids their separation into a distinct group containing "mostly cases which were formerly considered to be mild cases of typhoid has resulted in showing that true typhoid in the tropics is even a more serious disease than it was thought to be a few years ago. As, however, the general causes and conditions are the same which produce and disseminate these enteric fevers, and as the symptoms and treatment are much alike in all, it will be only necessary here to describe typhoid fever and the precautions that should be taken to avoid this disease, for the same precautions that prevent typhoid will also be effective against the paratyphoids. 
Typhoid fever attacks the young rather than the old, the most susceptible age being from 16 to 24. In the English Army in India it is always a disease which the young soldiers run a considerable risk of contracting, but that risk has been materially lessened by antityphoid inoculation, which tides over the most susceptible age.

The period of incubation, or period that elapses between the time when the infectious

Period of incubation and course of typhoid feyer. material has been taken into the body and the time when the patient begins to be ill, varies generally from seven to fourteen days, occasionally it may be a little longer. During this time there may be a feeling of tiredness and disinclination or inability to work. The disease commences in different ways, sometimes with shivering, at other times with diarrhœa and pain in the abdomen, and at other times with bleeding at the nose. Accompanying this are weakness and fever, which generally force the patient to take to bed. Along with the fever, which is higher in the evening and soon reaches $103^{\circ} \mathrm{F}$. or $104^{\circ} \mathrm{F}$, there is head- 
ache and maybe wandering at night. The tongue is coated and white; the bowels may be loose or constipated, and towards the end of the first week there may be rose-coloured spots on the body, especially on the abdomen. In the second week the fever continues high, there is a good deal of mental confusion and the patient is dull; the diarrhœa, if present, increases; the abdomen becomes swollen and tender, the pulse rapid, and the patient weaker and duller. In the third week the fever begins to fall, and in some cases, beyond great weakness and emaciation, no very pronounced symptoms occur; but in others, the diarrhœa, tenderness and distension of the abdomen become worse, delirium occurs, cough from lung trouble sets in, and there is special danger of the patient dying from failure of the heart's action or from perforation of the bowels, owing to the ulcers in the intestines, which are one of the important features of the disease. In the fourth week convalescence as a rule sets in, the temperature falls to normal or even below, the tongue cleans, the intellect becomes clear, the diarrhœa stops, and the appetite 
returns. In other cases, however, the patient's condition becomes worse, there is increasing weakness, the expression becomes heavier, the tongue and lips dry and covered with darkcoloured matter, and the patient falls into a condition of stupor and low muttering delirium, with loss of control over the excretory functions of the body. This stage is attended with extreme danger to the patient and often ends in death. But even from this stage the patient may recover after a protracted convalescence.

Great care has to be taken during the period of convalescence, whether it be from a mild attack of typhoid fever or a severe attack, that only the lightest and most digestible food is given. The appetite is often ravenous, and many persons have lost their lives after having successfully passed through the disease because of eating unsuitable food and too great quantities, which have brought on a relapse or caused perforation of the bowel.

The disease is caused by a bacillus or germ known as the enteric or typhoid fever bacillus. This generally gains

Causation. an entrance into the body 
through the alimentary canal, being swallowed in food or drink or by infection of the mouth through touching it with infected hands. It may on occasion, however, enter by means of the lungs. Once swallowed it begins to multiply in the bowel, causing certain ulcerations in the mucous lining, enters the bloodvessels, and is to be found in the blood. Having reproduced itself in enormous numbers, it leaves the body in the discharges from the bowel and in the urine. In

Mode of exit of those cases in which it attacks infection from the body. the lungs the bacillus is found in the sputum coughed up by the patient; clothes or bedclothes soiled with these discharges, utensils receiving the discharges, the hands of patients unless kept clean, the hands of nurses unless washed and disinfected, and any place where these discharges are thrown or deposited become infected with the living germs of the disease.

To prevent spread of the disease, therefore, from the sick room, to others in the house or to neighbouring houses, all evacuations should be received in utensils containing a disinfectant 
such as carbolic acid, cyllin, Prexention of the Jeyes' fluid, or corrosive subspread of typhoid fever.

limate; all soiled linen and other articles of clothing should be placed at once in a solution of one of these disinfectants and should remain in the solution for two hours. This removes stains and disinfects the articles. But to make the disinfection certain they should afterwards be boiled in water for a quarter of an hour. All cups, spoons, \&c., used by the patient should be immediately placed in a solution of carbolic acid, Jeyes' fluid, or cyllin, and afterwards scalded with boiling water; the patient's hands should be washed in water containing cyllin or izal; after attending the patient the nurse should wash her hands in water containing a similar disinfectant, then in hot water, scrubbing her hands with a nail-brush. The motions, urine, and sputum after thorough disinfection should be either boiled or buried at a depth of at least $2 \mathrm{ft}$. in the earth, and before being covered with earth have added to them any of the disinfectants previously mentioned or chloride of lime. The utensil 
itself should be thoroughly disinfected in addition. This is best effected by boiling it in water containing a disinfectant. Cloths or rags used for cleaning the patient after evacuation of the bowels should be immediately placed in water containing disinfectants and boiled, Destruction of or should be burnt. By these the infectious means the infectious material material imme- is destroyed immediately it the body all im- leaves the body. If it is not portant.

clestroyed at once it is liable to contaminate food and drink, multiply in these, and then gain an entrance into the body of some healthy person.

The patient continues to discharge these germs in the urine and bowel excreta during Modes of dis- the period of convalescence, semination of and it is important while this typhoid fever. happens that both urine and fæces should be thoroughly disinfected. In some cases, only a small percentage fortunately, the patient even after convalescence continues to discharge infective urine and infective fæces, and this may go on intermittently for years, the individual being to all appearances 
in perfect health. These are called typhoid carriers. Similarly there are paratyphoid carriers. These carriers coming into a healthy locality or a healthy house are liable to infect the inhabitants with typhoid or paratyphoid fever. Carriers who were cooks have been proved to have infected family after family that they have resided with. Carriers engaged in dairy work have also infected the milk which they were dealing with, and have thereby caused outbreaks of typhoid among those who have drank the milk. Carriers engaged in any employment connected with the handling of food or drink are dangerous to the community, and any person proved by a competent bacteriologist to be a typhoid carrier should be debarred from such occupations.

If by throwing the discharges containing the bacillus on to the ground the germ of typhoid fever reaches the well of the house, or a neighbour's well, or the public well, the people who drink that water will become affected by typhoid fever; or if the discharges are thrown on to the ground the infection 
may be taken into the house on boots or on utensils which have been placed on the ground. All insanitary conditions favour the spread of typhoid fever, especially an improper disposal or absence of disposal of excrement and urine. And it is because of the great defects in the disposal of sewage and the many contaminated wells in the tropics that typhoid is so prevalent. When the storage, collection, and disposal of sewage are bad, and infected sewage is not thoroughly disinfected or covered, flies swarm on to it, feed upon it, and soil their bodies and legs with it, and then afterwards alight on food or on utensils intended for or containing food or drink; or they drop into milk, contaminating with infectious matter whatever they touch. This smearing of utensils and contamination of exposed food or drink by flies are a common but unsuspected means by which infection spreads in localities where flies exist.

The dissemination of typhoid fever occurs accordingly by flies feeding on infected matter, and their infecting food or drink or utensils, and by contamination of the soil, 
water, or fcod by means of the typhoid bacillus, and as the bacillus is in the motions, urine and sputum of typhoid patients there is the risk of the spread of the disease whenever these are not thoroughly disinfected. Thus it happens that at one time it is an infected soil which produces the disease, at another time infected water, at another infected milk or food, at another infected salads taken from gardens fertilized with human manure, and at another time infected oysters or mussels which have been grown in sewage-contaminated water.

All drinking water and milk should be Precautions boiled. The typhoid bacilagainst typhoid lus is unable to withstand fever. thorough boiling even for five minutes, and if this precaution is taken with these important articles, quite three-quarters of the risk of contracting typhoid fever in the tropics disappears. Salads and uncooked vegetables ought not to be eaten in the tropics unless they have been carefully washed with boiled water and the whole process has been supervised personally. Servants cannot 
be depended on to take the requisite precautions. Oysters should also not be eaten unless some guarantee is given that they are not reared in water which is liable to sewage pollution even in the slightest degree. It is safer, however, to deny oneself the pleasure of the partaking of oysters. Food should not be eaten cold. Hot food, even although it has been previously exposed to infection, has this infection destroyed by cooking. All food and drink should be covered and protected by wire gauze from flies and other insects.

The utmost cleanliness should be insisted on in all latrines connected with the house and its premises, disinfectants being freely used in the utensils. The latrines should be mosquito-proof to protect them from the entrance of mosquitoes and flies. If the contents of the latrines are taken away by the local authorities in pails or carts, the pails or carts should always be thoroughly cleansed and disinfected by the local authorities before being brought back to the house premises. Any neglect of this very necessary measure should be immediately reported and action 
insisted on at once. Everyone going to the Eastern tropics should be vaccinated against typhoid and paratyphoid fever in order to tide over the first two years, which cover the most dangerous period.

\section{Mediterranean or Malta Fever.}

The name Mediterranean or Malta fever conveys the impression that this disease is confined to the shores of the Mediterranean or to the island of Malta. This is not so, for it is also prevalent in many regions of the tropics. The name, however, denotes where the disease was first recognized. Malta fever was formerly confounded with malaria and typhoid fever. But in 1887 it was shown by Sir David Bruce to be due to a special microorganism, and thus established to be a distinct disease. This micro-organism can live outside the body for a long period, on or in various articles it may reach. It is discharged in the excreta of patients suffering from the disease and occurs in the milk and urine of infected goats and cows, but does not appear to cause any special illness in them. In infected 
districts the micro-organism has been found in horses, sheep and dogs.

The illness, like relapsing fever, is characterized by a series of attacks of fever broken by

Symptoms. periods of normal temperature. This may continue for several months, and consequently renders the individual very weak. Fortunately, it is not a very fatal disease.

One of the chief precautions is under no circumstances to drink milk unless it is boiled,

Prevention. and especially is this needed with reference to goat's milk. In Malta it was found that 50 per cent. of the goats were infected. Goat's milk was accordingly forbidden to be used in the Navy and Army in Malta, with the result that there has been a very remarkable reduction in the incidence of the disease in these Services. As insanitary conditions contribute to the prevalence of the disease, it is important that scrupulous care should be taken with reference to the cleanliness of the dwelling and its surrounding, and especially as regards the kitchen and the health of the cook. 
In the event of anyone being ill with Malta fever, the discharges from the bowel and the urine should be thoroughly disinfected by immediately adding to them a solution of corrosive sublimate of the strength of $I$ in 500 , and allowing this disinfectant to act for an hour before carefully disposing of the sewage. Spoons and articles used by the patient should be placed in water with a disinfectant such as cyllin or other of a similar kind and boiled.

\section{Cholera.}

Cholera is caused by a microbe, curved like a comma. When this comma bacillus

Causation. is swallowed in considerable quantities in infected water or food it multiplies in the bowels, and in the process of multiplication produces a poison. This poison becomes absorbed

Symptoms.

in the system and gives rise to vomiting, violent purging and collapse, which may end in death in a few hours. The bowel discharges contain large numbers of the bacilli. Sometimes the microbe invades the whole body and is found in the blood. In 
these cases the bacilli are not only in the bowel discharges but also in the urine of the patient. The microbe can grow under favourable conditions outside the body as well as in the bowels of man. It grows in the soil of certain tropical regions in which the disease is endemic, such as the delta of the Ganges. It can be conveyed elsewhere beyond these endemic regions by the agency of infected articles or persons. If it finds suitable conditions of temperature, of soil and water in the new locality into which it has been carried, the microbe multiplies and converts this new locality for the time being into an epidemic area.

A cholera patient is not dangerous to others if care is taken to disinfect and destroy the A cholera patient bowel discharges, the urine, not dangerous to others if certain and soiled linen; but should precautionstaken. this precaution be neglected and the microbes gain access to food or drinking water by the agency of flies or by uncleanliness, then, as in the case of typhoid fever, the patient becomes a source of danger not only to the household but also to the neighbourhood. Whoever eats the contaminated 
food or drinks the contaminated water is likely to be attacked by the disease. A patient after convalescence from cholera may occasionally, like a typhoid patient, become a carrier of the disease owing to discharging at intervals cholera microbes from the bowel. Such an individual is dangerous and may carry the infection into healthy localities.

An attack of cholera may be preceded by diarrhœa for a few days, or it may occur suddenly, especially in the early hours of the morning. Unless immediate treatment is Immediate treat- adopted, and not infrequently ment necessary. in spite of treatment, the patient rapidly becomes collapsed and dies in a few hours. No diarrhœa, however slight in its nature, should be neglected in a cholera country or at the time of cholera epidemics. Medical assistance should be sought for at once in order that the diarrhœa, if possible, should be checked. In the case of cholera medical assistance should be sent for immediately. Every moment is of importance, and in the meantime until the doctor arrives an anti-cholera pill should be taken, or a dose of 
chlorodyne, or ten drops of laudanum and the same number of drops of dilute sulphuric acid in a little water. If these are not in the house, a wineglassful of vinegar and water taken in sips at short intervals may prove useful. Keep the patient in bed and warm, apply a mustard plaster to the abdomen, and give small pieces of ice to relieve thirst.

To prevent any contamination of food and water, the discharges, including urine, should Toprexent spread be received in a vessel and of the disease. then covered with a solution of carbolic acid, made up of $7 \mathrm{oz}$. of crude carbolic acid to a gallon of water, or other disinfectant, and if possible boiled. If they cannot be boiled they should, after disinfection, be buried deep in the ground, far away from any well ; they ought on no account to be thrown into the latrine or on the surface of the ground. Soiled linen and clothing, utensils, spoons, \&c., used by the patient or nurse, or which have been in the sick room, should be boiled. Those articles of clothing that cannot be boiled should be burnt. The hands of the nurse and patient should be washed in water to which 
carbolic acid, cyllin, izal, or other disinfectant has been added.

The precautions against cholera resolve themselves into drinking no water or milk unless it has been thoroughly

Precautions. boiled, eating no food or vegetables unless fresh, properly cooked, and protected from flies, and being careful as to the sanitary arrangements of the house. All excreta should be covered even when disinfectants have been added to them, to prevent access of flies to them. To prevent the spread of cholera when it does occur in a house, a careful destruction of the infective matter must be carried out, in addition to the other precautions recommended. In the event of being obliged to go into a cholera district during an epidemic, it is advisable to be inoculated against cholera. The operation is simple, and consists in the injection under the skin of a specially prepared prophylactic. The vaccine causes a slight indisposition, with fever and headache and pain at the seat of the inoculation for twenty-four hours, but the pain is not greater than that caused by an ordinary 
vaccination against small-pox. The protective effect of the cholera inoculation is secured in about four days and continues for at least twelve months, and usually much longer.

\section{Dysentery.}

Dysentery is essentially an inflammation of the inner lining of the large bowel, followed

Causation. at a more advanced stage by erosions of the mucous membrane and burrowing ulcerations of the submucous tissue involving the muscular coat of the intestines. There are several kinds of dysentery, which may be divided into protozoal, bacillary, and irritative. The protozoal is due to minute parasites of an animal nature that have been swallowed in food or drink. For instance, certain amœbæ produce what is called amœbic dysentery. This is commonly the form that goes by the term tropical dysentery. Bacillary dysenteries are due to the swallowing of microscopic bacilli which belong to the vegetative kingdom. They are also to be found in the tropics. The irritative dysenteries are generally due to swallowing substances of 
an irritative character, such as sand and mud. Drinking of muddy waters which contain neither the special dysenteric amœbæ or bacilli in them may cause this form of disease, so also may special wet conditions associated with cold and debility. Anything that disturbs the nutrition and circulation of the blood in the bowels is apt to predispose to dysentery. Thus a chill brought on by inattention to the ordinary rules of living, or by exposure to the vicissitudes of the weather, the eating of coarse and indigestible food, a defective diet, drinking of polluted water or water with much suspended mineral matter in it, and dwelling on an excretapolluted soil, are all probably exciting causes. It is not infrequently associated with other diseases, such as malarial fever and derangements of the liver. Sometimes it assumes an epidemic form, due to the pollution of drinking water by the specific germ, or the contamination of food, hands, or clothing by infected excreta, or by flies from infected and exposed latrines, while at other times it is due to the germ being communicated from one person to another by insanitary latrines, and in other ways. 
Dysentery may be mild or severe. In its severe form serious lesions in the bowels are produced, which, when the disease is recovered from, may interfere with comfort and health, and render the sufferer more or less an invalid for life. It is therefore a disease which, though its mortality is seldom great, it is important to avoid, and which, if unfortunately contracted, should never be neglected however mild it may be. A sequel of amobic dysentery may be abscess of the liver.

The disease may come on suddenly, but is usually preceded by ordinary diarrhœea, to which are soon added griping

Symptoms of disease. and straining. The desire to go to stool becomes incessant, little is passed other than slime or mucus mixed or streaked with blood. The straining and griping are most distressing, and the small quantity of blood and mucus passed gives no relief.

Dysentery is a disease which should be attended to at once, and its course cut short

Treatment.

as soon as possible. There should be no delay in sending for the doctor. Until the doctor arrives, an 
enema of warm water, plain or with a tablespoonful of boracic acid added, may be used to wash out the bowel; the patient should go to bed, a mustard plaster or fomentation should be applied to the abdomen, and only liquid food taken.

For mild cases of dysentery one or two teaspoonsful of castor oil with 20 drops of laudanum, or a similar dose of castor oil emulsion may be given night and morning with good results ; but for the severer forms, in which there is no solid matter but only blood and mucus in the evacuations, then either ipecacuanha or magnesium or sodium sulphate must be given. If no doctor is at hand, Io drops of laudanum may be taken, followed in half an hour by $20 \mathrm{gr}$. of ipecacuanha in capsules or pills. These should be taken on an empty stomach, and the patient should remain in bed as quietly as possible in order the better to resist any tendency to sickness which the drug is apt to produce. In those cases, however, in which vomiting occurs, it is better to substitute sulphate of magnesia or sulphate of soda. A teaspoonful of Epsom 
salts dissolved in an ounce of water, to which 5 drops of dilute sulphuric acid and a little cinnamon water have been added, given four or five times a day and continued for one or two days until the blood and mucus have disappeared from the stools, has, as a rule, proved very beneficial. During the illness, and until the motions become solid and natural, the diet should be sparing in quantity and consist mainly of thin soup, barley or rice water, boiled milk and sago. Emetine has been found a most efficient treatment for amœbic dysentery.

The most important consideration, however, is prevention of the disease, and for that purpose the same precautions Prevention. are to be taken as set down against malarial fever, chill, cholera and typhoid fever. Cleanliness of the house and surroundings must be insisted on. Special care must be taken to boil all drinking water and milk. To secure the purity of the water used for drinking or domestic purposes, and the cleanliness of the kitchens and latrines, and protection of both of these from flies, 
particular precautions as to the freshness of all foods and their protection against flies and insects are necessary. Salads should not be eaten. Supervision should be exercised over the servants, especially the cook, as to their state of health and the cleanliness of their clothes and person. Fevers and chills must be avoided, for they are important factors in the causation of dysentery owing to the engorgement of the internal organs which they induce. Special attention must be paid to securing digestible and suitable food and warm clothing, while every care should be taken to protect the system against the weather, especially cold and damp, and the more so if fatigued or in a low condition of health. Habitual constipation and an excessive amount of alcohol and meat should be avoided. All motions from a patient suffering from dysentery should be thoroughly disinfected with Jeyes' fluid, cyllin, kerol, or some similar disinfectant before being disposed of. The best disposal is boiling. 


\section{Plague.}

A little over twenty years ago plague was looked upon only with an historical interest. The disease, which had created so much terror and committed so many ravages in the fourteenth, fifteenth, sixteenth and seventeenth centuries was considered to be as extinct as the dodo. To-day plague is no longer historical, and since 1894 it has spread from China to nearly every tropical country of the world, and has once more become a disease which has to be counted with again as a formidable danger to communities even in Eastern and Central Europe. Since 1896 this disease has caused in India alone some ten million deaths.

The disease is caused by a microbe which has a peculiar liking for the lymph glands of the body, and is generally characterized by high fever, early delirium, and swellings, which are called buboes, in the armpit, neck, or groin. In some cases the microbe attacks the lungs and produces pneumonic plague; in others it is in the blood and causes septicæmic plague. In pneumonic plague the sputum brought up 
with the cough is blood-tinged, and swarms with plague bacilli. On account of this it is very infectious, and anyone closely associated with a pneumonic case of plague is apt to contract the disease. There is also a form of plague without buboes; it is called septicæmic plague. Like pneumonic plague it is very infectious. On the other hand, plague with buboes does not possess that extremely infectious property, and is not dangerous to others in the same way. The modes of infection depend on the form

The modes of infection. that the disease assumes. The bubonic form is generally caused by the bites of rat-fleas (fig. 26) which have become infected by feeding on plagueinfected rats, plague being primarily a disease of rats. The rat-flea leaves the body of a dead rat, and if there are no live rats to migrate to. it attacks man when the opportunity arises. The two chief species of rat that disseminateplague are Mus rattus and Mus decumanus. Bugs as well as fleas can spread plague. The pneumonic and septicæmic forms of plague are generally spread independently of infective: 
Fleas which transmit Plague.

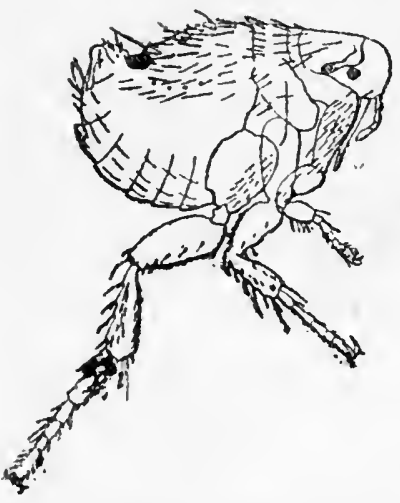

a. Cenopsylla cheopis.

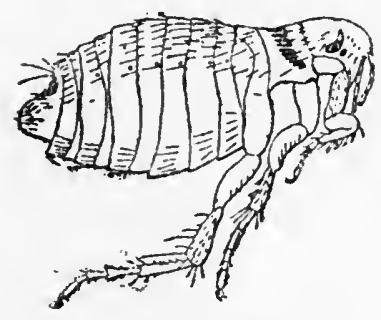

c. Ceratophyllus.

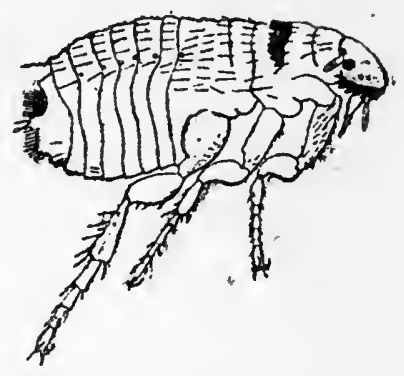

b. Ctenocephalus.

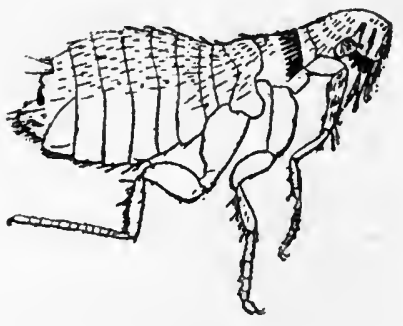

d. Clenopsylla.

FIG. 26. $-a$, rat-flea, common in warm countries; $b$, the dog-flea, also found on the cat and rat; $c$, rat-flea, common in Europe; $d$, mouse-fiea, also found on the rat. 
rats and are caused by infection with the bacilli coming from the plague patient. In the case of septicæmic plague the bacilli contained in the excreta and urine of the patient may contaminate food and hands and clothes, and the infection may thus find entrance into the mouth of a healthy person in much the same way as the infectious matters from a typhoid patient. In the case of pneumonic plague there is direct infection, as has been stated, from the sputum and droplets from the mouth, discharged in the process of coughing. These infective discharges from pneumonic and septicæmic cases are liable to infect rats with plague, and these in turn spread it to other rats and man.

The first and foremost rule is to live in a dry, clean, well-lighted and well-ventilated Rules to be house, free from rats. The adopted xith the next rule is to preserve a object of protection against good state of health by plague in a plague- regular living; and the third stricken district. is to be inoculated against plague. Plague will not flourish in a sanitary house, and no house can be said to be sanitary 
if, in addition to good lighting and ventilation, it is not free from rats and fleas. If there are any rats, measures should be taken at once to poison them and to remove any conditions which are liable to harbour them. The lower floors should be made rat-proof. Good health is maintained by attention to the general hygienic regulations conformed to in ordinary times. Excesses are to be avoided, or anything that is known to lower the state of health.

Inoculations are useful against accidental exposure to infection, either by infected fleas, rats or food, clothes, or in houses which may be infected, and which are in an insanitary state. Haffkine's prophylactic produces slight indisposition for two days, and pain at the seat of the inoculation for several days longer, but it secures a strong protective effect for at least twelve months. Yersin's prophylactic serum produces less local reaction, but its protective effect does not last more than ten days or a fortnight. Nurses who have to attend plague cases should always previously be inoculated; they should also be careful to disinfect their 
hands, never to eat their meals in the same room, and to enjoy regularly a few hours out of doors every day.

\section{WORMS.}

The two most important worms which cause disease in the tropics are the ancylostome and the bilharzia. The diseases they produce are called ancylostomiasis and bilharziosis. There is a third worm, the Guinea worm, but it is neither so extensive as the others in its geographical distribution nor does it cause so serious a disease.

\section{Ancylostomiasis.}

The ancylostomes causing ancylostomiasis obtain a lodgment in the bowels, where they fix themselves by suckers and hooks and

Symptoms. nourish themselves with the blood which they draw from the bowel. They thus produce a gradually increasing bloodlessness, or anæmia, with weakness and disinclination to work and uneasiness or pain generally in the region of the stomach. If the infection of the worms is 
large and remains untreated it may lead to serious symptoms, and finally to heart failure and death.

The female worms in the intestines lay a large number of eggs which, mixed with the fæces, leave the body when

Mode of infection. the bowels are moved. The eggs hatch outside the body and the larvæ undergo their development in damp earth, in mud or in muddy water. There they remain until they are transferred by hands soiled with the infected earth or mud to the mouth of an individual, or they are swallowed in muddy water. In both instances they ultimately reach the small or large bowel. Having reached their destination, they fix themselves on to the mucous membrane of the bowel and undergo further development into the adult worms. Another mode of infection is through the skin. The larvæ coming in contact with the skin can penetrate its pores, enter the circulation of the blood and reach the intestines in this way. Hence anyone wading or bathing in muddy water which contains these larvæ, or stepping with bare feet on to mud thus 
contaminated, is liable to become infected with ancylostomiasis through the skin.

The most important measures for preventing the spread of the disease are the provision of good latrines and a safe dis-

Measures of prevention.

posal of the excreta, coupled with a supply of good and uncontaminated drinking and bathing water. These are very much neglected in the tropics. The contamination of the ground with excreta and of water in ponds and pools, and of muddy banks of rivers and watercourses, is a very common occurrence. The disease is also often spread by coolies or labourers suffering from ancylostomiasis coming from infected localities into healthy districts and on their way infecting the principal routes by which they travel. Whenever large numbers are brought together from different parts of a country, such as occurs in mines, plantations, railway stations and large public works, there is always risk of the introduction and spread of ancylostomiasis unless adequate precautions in the direction mentioned are taken. Preventive measures should be taken by the responsible company or local 
authority under the advice and supervision of their medical officer, who at the same time will treat all infected coolies with the object of destroying the worms and therefore the infecting agent. As regards personal precautions, these should include the boiling of all drinking and bathing water, never bathing in muddy pools, the wearing of boots and leggings or putties when travelling, the careful selection of latrine accommodation, and scrupulous cleanliness of the hands at all times and particularly before eating.

\section{Bilharziosis.}

Bilharziosis is caused by a worm which finds its way into the veins in connection with the abdominal organs, more especially with the bladder and bowel. There the female lays its eggs, which by means of a spine on each pierce the mucous membrane of the bladder or bowel, set up much irritation and inflammation, and are voided in the urine or fæces. The first is by far the most common.

In those cases in which the eggs leave the body with the urine, the most prominent 
Symptoms.

symptom is the passage of blood towards the end of micturition, and it may be accompanied by much irritation and pain. In those other cases where the eggs leave the body by the bowels they may set up dysenteric symptoms, with the passage of mucus and blood and much straining.

Like the infection of ancylostomiasis, that of bilharziosis is acquired through the skin. The eggs when voided hatch Mode of either in the urine or when infection. they reach fresh water; from each egg a ciliated larva emerges and swims about freely. Later the larvæ pass into the body of a mollusc, if present in the water, and undergo several stages of development ; finally they escape from the mollusc into the water, and, when opportunity arises, pierce the skin of anyone wading with bare feet in that water, and ultimately find their way into the selected veins in the abdomen. Similarly the larvæ can find their goal when swallowed.

Care should be taken when wading in any drain, streamlet, or river, in which bilharzia 
Prevention. larvæ are likely to be, to be well protected by wearing long waterproof boots and waders, and not to drink the water unless it has been boiled. To prevent water becoming infected with the eggs and embryos of bilharzia of a patient with the disease, care requires to be taken that both urine and frecs are received in proper latrines and that the contents of these are disposed of in such a manner as to prevent any possibility of water becoming contaminated.

\section{Diseases of the Liver.}

In the tropics the liver of Europeans is particularly susceptible to disorder. Every meal produces physiologically a certain amount of active congestion of the liver, which is intensified if the diet is rich and excessive in quantity, and alcohol is taken. Formerly, when the conditions of healthy life in the tropics was less understood, when little was done to mitigate the injurious effects of the heat or to avoid chills, when heavy and frequent meals, consisting of meat and rich curries, were washed down with beer and 
strong wines, liver diseases were conmon. A painful and tragic experience has but too well demonstrated the fact that it is necessary for a European, when transferred to a warm climate, to modify his mode of life and adapt it to his new environments; European habits of life must at all events be partially discarded if good health is to be enjoyed in the tropics, and in proportion to the extent to which this adaptation has been effected and sanitary laws obeyed tropical liver affection and tropical liver abscess have lessened in frequency. Regular exercise, attention to the bowels, proper protection against the sun, well-ventilated rooms which are not draughty, the dispensing with heavy tiffins at midday and the more moderate use of alcohol, have worked a wonderful change in this respect.

It is unnecessary to enter here into the several forms of liver diseases which may be contracted in the tropics. They may be summed up as mainly the effects of acute and chronic congestion, ending sometimes in abscess. Abscess of the liver may, however, also follow an attack of amœbic dysentery, 
which renders the early treatment of dysentery all the more important.

Acute Congestions are usually brought about by a chill contracted, it may be, by exposure to rain or to a cold wind or draught, while fatigued or after violent exercise; or to exposure to night air in unsuitable clothing, after the hot and impure air of a public assembly or dance, or to a cold bath when exhausted, or to any cause which suddenly checks the perspiration, and drives the blood into the internal organs.

Pain and uneasiness on the right side, discomfort in breathing on lying on the left side, yellowness of the eyes, sleepiness and slight fever, are the more prominent symptoms.

If medical advice is not within reach, palliative measures may be taken until the doctor arrives. These consist in taking a warm bath, going to bed, and placing over the right side, where the pain is felt, a mustard plaster, or a poultice with mustard, or a flannel put into hot water, wrung out, and sprinkled with turpentine. An aperient pill, followed in the morning with a dose of Apenta water or 
Epsom salts, should also be taken. At the same time the diet should be restricted to milk and light puddings.

Chronic Congestions are more frequently due to long-continued residence in the tropics, and exposure to constant high temperature, together with a too stimulating diet, a sedentary habit of life, and sometimes repeated attacks of malaria. The best remedy is a change to a more temperate climate or a sea voyage. Great benefit is usually obtained by a careful course of mineral waters and baths under medical advice at one or other of the health resorts in Europe. Of those in Britain, Bath, Harrogate, Strathpeffer, are probably the most suitable for these kind of cases.

In dealing with sunstroke, cholera, dysentery, and acute congestion of the liver, some simple form of treatment has been added to the measures of prevention. This has been done because the diseases are such that, if not attended to at once, they are likely to prove dangerous to the patient. To attempt to treat oneself when ill is highly imprudent, and is seldom successful. There are, however, occa- 
sions on which a sudden emergency arises when far away from medical assistance, and when the illness or accident requires prompt treatment. In these cases the resort to some simple remedy until the doctor arrives may be invaluable. Snake-bites, insect-bites and wounds require remedies to be applied at once, and for this reason they are dealt with here. 


\section{CHAPTER V.}

\section{SNAKE-Bite.}

Venomous snakes are classified as vipers and colubrines.

The deadliest vipers are: in India the Russell's viper; in Africa the puff-adders; in

Yipers.

America the bushmaster, the fer-de-lance, the mocassin or cotton-mouth, and the rattle-snakes.

The deadliest colubrines are: in Asia the cobras, the kraits, and the sea-snakes; in Africa the cobras and the large green

Colubrines.

tree snakes (Dendraspi); in Australia the copperhead, the brown snake, the tiger snake, the black snake, the spinetailed death-adder, and the sea-snakes.

All of these are poisonous, but the majority

Safest to treat all snakes-bites as poisonous. of snakes in a country are, as a rule, not poisonous. It is safer, however, if bitten by 
a snake to act as if it were poisonous, unless there is certain proof that it is not so.

A venomous snake, with its two poison fangs, leaves a different kind of wound from a harmless snake with numerous teeth. An examination of the wound will often at once decide this question. A poisonous snake will produce two red punctures on the skin about one inch apart, whereas a harmless snake will leave a row or double row of punctures. The punctures can generally be seen by the naked eye, but at times may require a magnifying glass for their recognition. The symptoms of snake poisoning are not long Symptoms. in making themselves evident. No time should be lost in applying remedial treatment. The symptoms depend on the size and kind of snake, also the amount of poison injected with the bite, and whether the snake has recently emptied its poison sac by biting something else. Children and people in a bad state of health withstand the effects of the poison less than the strong. The symptoms differ somewhat in the cobra and the viper. With the viper the local pain is very severe, 
and there is usually very great swelling and local extravasation; there is more tendency to syncope, and there is likely to be subsequent gangrene and blood-poisoning. With the colubrines the local symptoms are very much less severe. Indeed with the sea-snakes there may be no local symptoms at all. If recovery takes place there are, except in the case of bites from kraits, no sequelæ to speak of.

The chief symptoms following the bite of a poisonous snake are pain and swelling at the seat of the wound, gradually spreading up the limb, faintness, sickness, vomiting, inability to stand, difficulty of breathing, gradually slowing down to suffocation, coldness of the body, feeble pulse, and death occurs either by suffocation, convulsions, or paralysis of the heart.

The various antivenins, specific and synthetic, which are now prepared in several

\section{Treatment.} countries, are when employed with precise knowledge of the case and early enough, complete antidotes to snake-venom; but they can only be used by a medical man and often are not procurable. Medical assistance should be sent for imme- 
diately, but local treatment should be begun at once. A snake-bite admits of no delay in its treatment. Promptness gives the individual a good chance of recovery. To wait to see if any illness ensues means most likely the deathwarrant of the patient.

The great object to attain is to prevent the poison getting into the general circulation of the blood. With that view, as the bites are generally on the hands, or feet, or legs, or arms, a stout cord should be tightly twisted round the fingers, toes, or limb, a few inches above the wound. That is, the cord has to be tied round the part, so as to be between the bite and the heart, i.e., to intercept the circulation. A second ligature or cord should be bound round the limb a little higher up. Time should not be wasted looking for 'cord. If none is at hand a twisted handkerchief, bandage, piece of cloth torn from a garment or sheet may be bound round the limb. The necessary tightness should then be secured by placing a stick underneath the article used a ligature, so that it will be between the ligat, and the limb, and then twisting the stick. 
Having applied the ligature, the bite should be freely washed with a 5 per cent. solution of permanganate of potash, or, better, permanganate of zinc, and some of the solution should be injected into the tissues round the bite with a hypodermic syringe. In the case of a viper bite it is not advisable to incise it on account of the danger of subsequent uncontrollable hæmorrhage due to action of most viper venoms preventing the blood from clotting, and consequently great difficulty in stopping the bleeding. Hunters, if bitten by a venomous snake, will, after the application of the ligature, incise the bite, pour some gunpowder into the wound, and then light the gunpowder with a match. This will cauterize the wound, the object of which is to destroy the poison. If there is no chemical at hand to apply to the wound to destroy the poison, the snake-bite, after being cut open, should be thoroughly sucked. In doing this, care should be taken to spit out immediately the blood and poison thus taken into the mouth, and also to rinse the mouth. Snake poison, taken by the mouth, usually produces no ill-effects, but there is 
always risk if there happen to be any abrasions in the mouth. After treatment of the wound, the higher ligature may be removed, otherwise, if kept on too long, the limb, not receiving blood, may die. The patient should be kept at rest and warm; ammonia and spirits of ether, which are good stimulants, or alcohol in small doses, should be given.

In travelling where snakes are numerous always wear strong boots and good puttees Precautions to or leggings, never be withbe taken against out a good strong stick, snakes.

and observe where you are going. The hamadryad-which is called the king cobra, and may grow to about $14 \mathrm{ft}$. long-and the zambra are about the only snakes actually dangerous when met with. These inhabit damp and jungly places, and if disturbed may attack man. Other snakes will seldom bite unless accidentally trodden on, or in such a position that they cannot get away. Bath-rooms should always be well lighted, and should have nothing in them under which a snake can conceal itself. Old buildings in a state of dilapidation should be avoided. 
The stings and bites of insects-whether they be those of the scorpion, the bee, the

Treatment of stings and bites of insects. wasp, the spider, the centipede, or other insect-seldom produce more than local irrisation, pain, and swelling. Sometimes, however, by reason of the number of wounds they inflict, they may cause serious symptoms, or even death. Fatal results have sometimes followed from wounds inflicted by a swarm of bees or wasps. For relief of pain the wound, if possible, should be sucked. Cocaine relieves the pain of stings and bites of insects. A good application is a paste prepared with ipecacuanha powder and water, and smeared over the wound or wounds. If this is not at hand, some spirits of wine, vinegar, eau de Cologne, alum, tobacco juice, or ammonia should be applied. The sting of a wasp may be removed by pressing the opening of a watch-key over the part, first of all being careful to locate the exact position of the sting. Irritation of the skin and painful swellings caused by ants, spiders, beetles, sand-flies, or mosquitces may be treated with a solution of bicarbonate of 
soda, washing soda, or ammonia, or with vinegar, ipecacuanha, kerosene, or any of the essential oils, such as eucalyptus, cinnamon, \&c. These essential oils, when added to a mixture of infusion of quassia and native spirit, generally called $a r a k$, or to a solution of quinine, are useful applications to the hands, feet and neck to repel insects.

The sand-flea, commonly called the chigger, is apt to cause intense local irritation, inflam-

The sand-flea. mation and a painful sore. This is due to the pregnant female chigger burrowing into the skin and swelling up to the size of a pea, because of the numerous eggs she contains. If the skin is unbroken the black speck indicating the opening at which the chigger entered the skin should be enlarged by a needle, and the swollen chigger carefully extracted without breaking it. If not recognized until a sore is formed, a strong solution of carbolic acid should be applied locally.

Protection from sand-fleas is afforded by wearing strong boots when out on sand, or in huts, or other places in which they are likely 
to be present, and never to go about barefooted, even when in one's own house. Insect powder inside the boots, or oil of cloves on the feet, is an additional protection where these insects abound. 


\section{CHAPTER VI. \\ WOUNDS.}

THE frontispiece shows roughly the position of the arteries and veins, which are close to one another on both sides of the body. In the case of a serious Difference between bleeding wound of the arm or leg, from arteries one or other or both of these vessels may be cut, and very alarming bleeding ensue. It is essential that this bleeding should be arrested until medical assistance is obtained. The method of stopping bleeding from an artery is different from that necessary for a vein, so it is important to be able to distinguish between bleeding from an artery and bleeding from a vein. Blood spurting out in jets, with force, and bright red in colour, is from an artery. On the other hand, blood welling out from the wound in a continuous stream and of a dark colour is from a vein. The course of 
the blood-stream is also different in arteries and veins. In arteries it is from the heart towards the fingers and toes, whereas in the veins it is from the fingers and toes towards the heart. This difference is important to remember when endeavouring to arrest bleeding from an artery. The arterial blood is pumped from the heart towards the fingers and toes, and if the artery is cut it is obvious that to stop any bleeding from the cut the pressure on the artery must be made above the cut, or between the heart and the cut, and vice versâ, if a vein is cut the pressure must be below the cut.

The rule, therefore, is that if the blood is red and comes out in. jerks or spurts apply Where to apply pressure above the cut. If the pressure to arrest blood is dark and comes out bleeding. in great volume apply pressure below the cut. If there is both spouting and oozing apply pressure both above and below the cut.

Pressure of the artery or vein against the bone or bones behind it may be carried out by compression with the finger or thumb, or 
How to apply

with a pad above or below the pressure to arrest wound according to whether bleeding. the bleeding is arterial or venous, and by a handkerchief twisted tightly round the limb. The handkerchief or other kind of available bandage can be tightened, if found necessary, by placing a stick underneath it and twisting the stick. Care has, however, to be taken that the extra strong pressure shall not be continued longer than necessary, otherwise the limb, not being supplied with blood, may become gangrenous.

Often a simple pad over the wound and a bandage will be sufficient to stop the bleeding, particularly if it is from a vein.

For a small cut or irregular wound in which no large vessel is injured, the wound should

Treatment of be washed with water in which wounds. a tablet of carbolic acid or other disinfectant is dissolved, well dried, then painted with tincture of iodine and covered with boracic lint or ordinary lint. If the lips of the wound are gaping, they should be brought together by the application of thin layers of plaster and then covered. 
Wounds caused by bites of wild animals or of dogs which are suspected of being mad should be immediately cauterized with lunar caustic, or syringed with a strong solution of Condy's fluid or permanganate of potash. The same should be done to the wound caused by a poisoned arrow after cutting out the arrow.

Burns and scalds are best treated by the application of a mixture of olive oil and lime

Burns and scalds. water. If olive oil is not at hand, linseed or castor oil may be used. If there is no lime water the oil will do alone. Soak some lint in the mixture or oil and apply the smooth side of the lint to the scald or burn, and then cover with cottonwool to protect the injured part from the air. If oil is not available spread some vaseline or boracic acid ointment on the smooth side of the lint and apply, not forgetting to cover afterwards with cotton-wool. If blisters form, prick them with a clean needle and let out the fluid, but do not remove the skin.

Rest the injured part, and keep it cool by applying a handkerchief or cloth, dipped in 
sprains. vinegar or whisky and water. When the swelling has gone down rub with a liniment, and bandage.

\section{Medical Equipment.}

A case of medicines in a portable form, obtainable from any of the chief large manufacturing firms of chemists, will always be found useful for those going to the tropics, where, not infrequently, they may be stationed in a district some considerable distance from a medical man. The drugs taken are better to be packed in the solid form, when possible, as they keep better and are less liable to be lost in the event of bottles breaking. Tablets, as a rule, are the most convenient, but tablets of quinine, though useful for prophylactic purposes, are not so suitable for treatment of an attack of fever, as then the digestive system is often out of order, and the powder is more effective. The powder can be taken in milk. The tablets or "tabloids" are apt to become insoluble on keeping. A bottle of quinine, or euquinine powder for illnesses, is therefore preferable. If 
quinine tablets alone are taken they should always be broken up before use when taken on account of an attack of fever. A list of drugs and other appliances is appended. The drugs, with few exceptions, can be obtained in the form of tablets, "tabloids," palatinoids, or pills. The dose will always be on the bottle. Children should never be given opium in any form without medical advice.

Tea tablets are always useful when travelling; one or two dissolved in a cupful of boiling water secures a safe and agreeable drink.

\section{DRUGS.}

Aloin Compound Tablets.

Anti-cholera Pills or Palatinoids (Indian Government formula), with instructions how to use them.

Bismuth and Soda Tablets.

Blue Pill, Colocynth, and Hyoscyamus.

Caffeine Tablets.

Calomel Tablets.

Cascara Tablets, 2 gr.

Chlorate of Potash Tablets.

Chlorodyne, I bottle.

Compound Rhubarb Tablets.

Dovar's Powder Tablets.

Effervescing Ammonium Carbonate.

A. Acid Tablets. Citric Acid.

B. Alkaline Tablets. Ammonium Carbonate Compound. 
Epsom Salts.

Hazeline Cream.

Iodoform.

Ipecacuanha in powder, I bottle, and in tablets.

Phenacetin tablets.

Quinine Hydrochlorate, or Euquinine, I bottle, or in Tablets, with directions to crush before using.

Soda and Mint Tablets.

Tinct. Camph. Co., in $15 \mathrm{~min}$. Tablets (Paregoric), contains Opium.

Tinct. Opii, 5 min. Tablets (Laudanum).

Tonic Compound Tablets.

Vaseline.

Olive Oil.

I bottle of "Soloid" Aluminis, Io gr.

Lancet.

INSTRUMENTS, \&C.

Needles.

Scissors.

Clinical Thermometer.

Small Syringe, Glass.

Higginson's Enema Syringe.

Measuring Glasses in Case, a Minim Glass, and a 2 oz. Glass. An Eye Bath.

BANDAGES, \&C.

Bandages, $2 \frac{1}{2}$ in. wide.

Lint.

Plaster.

Silk.

Safety Pins to fasten Bandages.

Cotton-wool.

DISINFECTANTS.

One bottle of Cyllin, Jeyes' Fluid, Kerol, Izal, Cook's Co-fectant or Bacterol.

: Carbolic Acid Tablets (one in two pints of water). 
Boracic Acid Tablets.

Permanganate of Potash Tablets and Crystals.

Tincture of Iodine.

INSECTICIDES.

One bottle of "Soloids" of Corrosive Sublimate; $x$ "Soloid" to a half pint of water makes a solution of the strength of $I$ in 500 .

Soft Soap.

Jeyes' Fluid, Cyllin, Kerol, Izal, Cook's Co-fectant or Bacterol. Flowers of Sulphur.

Kerosene.

Petrol.

Creosote.

Oil of Turpentine.

Almond Oil.

Oil of Sassafras.

White Precipitate Ointment.

Guaiacol and Oxide of Zinc Powder.

Menthol and Oxide of Zinc Powder.

Decoction of Native Tobacco.

Vaseline.

Instructions are given in the case for the use of the Drugs. 


\section{JOHN BALE, SONS \& DANIELSSON, LTD.}

\section{Tropical and Sub-tropical Climates, and the Principles of Personal Hygiene in them, as Applied to Europeans. By W. J. SIMPSON, M.D., F.R.C.P. With many IIIustrations and Colonred Plate. Deniy svo, about 400 pages, cloth limp, gilt lettered. 15s. net, postage 6 d.}

Hints for Residents and Travellers in Persia. By A. R. NELIOAN, M.D.Lond., M.R.C.S., D.T.M. \& H.Cantsb. With Map. 5s. net, postage 4 d.

"Verb. Sap." on going to West Africa, Northern and Southern Nigeria and the Coasts. By CAPT. ALAN FIELD. Third Edition. 2s. 6d. net, postage 4 d.

\section{Health Preservation in West Africa.}

By J. CHAS. RYAN, L.R.C.P.I., with Introduction by Sir RONALD

Ross. 5s. net, postage 3d.

\section{Studies in Laboratory Work.}

By C. W. DANIELS, M.R.C.S.Eng., and H. B. NEWHAM, M.R.C.S.Eng. 16s, net, postage 6d.

\section{Tropical Medicine and Hygiene.}

By C. W. DANIELS, M.R.C.S.Eng. Demy 8vo, limp cloth.

7s. 6d. net each, postage 6d.

Part I (SECOND EDITION)-Diseases due to Protozoa.

Part II (SECOND EDITION)-Diseases due to the Metazoa. With an Article on Venomous Snakes by A. Alcock.

Part III.-Diseases due to Bacteria and other Yegetabie Parasites; those probably associated with certain articles of dlet as well as of unknown origin; others probably dirsctly or indirectly due to Moteorological and Climatic

Beriberi. Conditions.

By EDWARD B. VEDDleR, A.M., M.D. Illustrated. Royal svo, pp. 427 + viii, cloth. 18s. net, postage $6 \mathrm{~d}$.

The Diseases of China, including Formosa and Korea. By W. HAMLLTON JEFFERYS, A.M., M.D., and JAMES L. MAXWELL, M.D. Lond. With 5 Coloured Plates, II NosoOeographical Maps, and 352 Illustrations in the text. Octavo, pp, $720+x v i$, handsome cloth. 25s. net, postage 1s.

The Etiology of Endemic Goitre.

Being the Milroy Lectures for 1913. By ROBERT McCARRISON, M.D., R.U.I., M.R.C.P.Lond., Major I.M.S. With many plates and a map in colours. Demy 8 vo, pp. $216+$ vi, cloth, lettered. 10s. 6d. net, postage $4 \mathrm{~d}$.

\section{A Handbook of Practical Parasitology.}

By Dr. MAX BRAUN and DR. M. LUUHE. Translated by LiNvA Forster. Royal $8 \mathrm{vo}$, pp. $208+$ viii, crimson cloth, gilt lettered, gilt tops. 10s. 6d. net, postage $6 \mathrm{~d}$.

Field Service Notes for R.A.M.C. including Amendments. By MAJOu GOODWIN. 8s. net, postage free.

Gunshot Injuries: How they are Inflicted, their Complications and Treatment. By CoLONRL LOUIS A. LAGARDE. Published by Authority of the Secretary of state for War, U.8. Army. With 160 illustrations of wounds, projectiles, \&c. Royal 8vo, 18s. net, postage $6 \mathrm{~d}$. 
305 De Neve Drive - Parking Lot 17 - Box 951388

LOS ANGELES, CALIFORNIA 90095-1388

Return this material to the library from which it was borrowed.

F.

OCT 022002

ILL/INU

LCLA YRL/ILL

REC'D YRL

$$
\text { uLip } 42002
$$

b

E

3

$s$

c

\section{LONDON :}

$83,85,87,89,91$, GREAT TITCHFIELD STREET OXFORD STREET, W. 


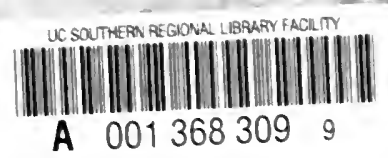

be

4,

A.

4

2

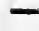

$-$ 


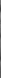
If -

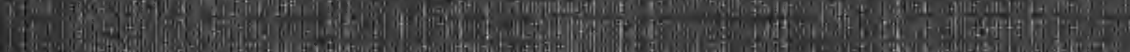
tock $6 y^{2}$ 3:

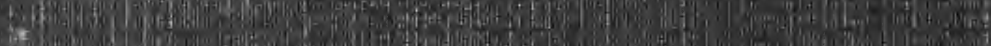

